\title{
Para uma análise pedagógica dos contextos educativos - uma entrevista com Anna Bondioli, Monica Ferrari e Donatella Savio da Universidade de Pavia//tália ${ }^{1}$
}

\author{
Catarina $\mathrm{Moro}^{2}$ \\ Gizele de Souza ${ }^{2}$
}

C.M \& G.S.: As professoras Anna Bondioli, Monica Ferrari e Donatella Savio são professoras vinculadas à Universidade de Pavia, no norte da Itália, e são pesquisadoras reconhecidas no seu país (como no Brasil) como profissionais comprometidas com a qualidade nos processos educativos de instituições de crianças pequenas, tanto na pesquisa como na formação de profissionais que atuam com a infância.

No Brasil, já circulam há muitos anos traduções de obras produzidas por essas e outras pesquisadoras da Universidade de Pavia e também em função das atividades de pesquisa que vimos desenvolvendo em colaboração (Universidade Federal do Paraná e Universidade de Pavia) propusemos a realização de uma entrevista que localizasse para o público brasileiro os percursos trilhados por elas, seus horizontes de estudo e as preocupações acadêmico-profissionais em torno da temática da infância, educação, avaliação e história. Lançamos o desafio e as colegas prontamente o aceitaram, posicionando-se de modo aprofundado a cada tema.

As questões propostas foram entendidas pelas entrevistadas como oportunidade e desafio que lhes solicitou e permitiu reunir e desenvolver diferentes dimensões: teórica e nitidamente pessoal; o registro individual e o de grupo; a perspectiva histórica e a atual. A entrevista articula-se em partes: a primeira relativa à história e à fisionomia do grupo de pesquisa pavese, intitulada História, fisionomia, âmbitos de pesquisa do grupo dos Professores de Pedagogia

DOI: $10.1590 / 0104-4060.46424$

1 Tradução de Luiz Ernani Fritoli. Universidade Federal do Paraná, Setor de Ciências Humanas. Curitiba, Paraná, Brasil. Rua General Carneiro, nº 460. Centro. CEP: 80060-150. E-mail: fritoli@ufpr.br

2 Revisão Técnica de Catarina Moro e Gizele de Souza. Universidade Federal do Paraná, Setor de Educação. Curitiba, Paraná, Brasil. Rua General Carneiro, n 460. Centro. CEP: 80060150.E-mails: moro.catarina@gmail.com; gizelesouza@ufpr.br 
da Universidade de Pavia. Nesta parte, cada questão foi respondida por uma das pesquisadoras da Universidade de Pavia como voz representativa de um posicionamento do grupo. A segunda refere-se aos percursos de formação e de pesquisa de cada uma das entrevistadas, chamada Os percursos de pesquisa e formação individuais dos atuais membros do grupo: Anna Bondioli, Monica Ferrari e Donatella Savio.

A.B., M.F. \& D.S.: Quando as nossas colegas Gizele de Souza e Catarina Moro nos propuseram uma entrevista para pôr em foco as perspectivas e os percursos de pesquisa dos programas pedagógicos da Universidade de Pavia, que atualmente representamos, aceitamos com prazer. Tratava-se de uma boa ocasião para repercorrer a história, os enredos de pensamentos e pessoas através dos quais veio a delinear-se o "nosso" modo de conceber a pesquisa e o conjunto de temas sobre os quais concentramos a atenção. Uma oportunidade, portanto, para especificar as nossas raízes e a "nossa" identidade como polo de pesquisa educativa e não somente: "declarar-nos" nos parecia sem dúvida também um bom modo para dar início à relação de colaboração e intercâmbio com as colegas brasileiras sobre a pesquisa.

\section{Parte I. História, fisionomia, âmbitos de pesquisa do grupo dos Pro- fessores de Pedagogia do Departamento de Estudos Humanísticos da Universidade de Pavia}

\section{C.M. \& G.S.: Como se constituiu o grupo de pesquisadores da área de educação na Università Degli Studi di Pavia? \\ A.B., M.F. \& D.S.: Os membros do "grupo" foram muitos e, principalmen-} te, mudaram no tempo em relação a diversas experiências de pesquisa-formação. Atualmente somos Anna Bondioli, Monica Ferrari (professoras titulares de Pedagogia Geral e Social) e Donatella Savio (pesquisadora de Pedagogia Geral e Social), todas parte do quadro efetivo da Universidade de Pavia, embora tenham sido também numerosos os doutorandos, depois doutores, que colaboraram ao longo dos anos, a partir da realização de suas teses, e ainda mais numerosos os especialistas externos (educadores e professores, diretores de escolas, coordenadores pedagógicos, inspetores técnicos do Ministério da Educação) com os quais tivemos a sorte de poder trabalhar. Egle Becchi, agora professora emérita da nossa Universidade, antes professora titular de Pedagogia Geral e Social, foi para nós todos o ponto de referência inicial e a coordenadora de tantos projetos de trabalho; de fato, não deixamos de colaborar com ela no desenvolvimento de alguns projetos, mesmo após a sua aposentadoria. 
O "grupo" de pesquisa teve, desde o início, uma caracterização particular. Cada membro pôde aventurar-se em âmbitos de pesquisa específicos, frequentemente neles encontrando a própria vocação. Ao mesmo tempo cada membro compartilhou com os outros alguns pressupostos de base, derivados de opções teóricas e metodológicas comuns. Em muitos casos os aportes de cada um se entrelaçaram com os dos outros; algumas escolhas de campo peculiares foram se delineando justamente com base nesses entrelaçamentos. Por isso podemos dizer que o grupo pavese se distingue pela atenção que, desde os anos setenta, destinou a algumas temáticas, em particular àquelas relativas ao estudo da infância e à educação infantil, e ao modo em que, nos trabalhos realizados individualmente ou em colaboração, demonstrou conceber a educação e a pesquisa em Pedagogia. A partir dessa matriz se desenvolveram diversos percursos de pesquisa aos quais contribuíram, de maneira mais ou menos exclusiva, alguns dos membros atuais do grupo. Entre as contribuições mais significativas podemos elencar os aspectos e os temas que distinguem o nosso trabalho comum e em torno dos quais se concentraram nossos interesses de pesquisadores:

a) o diálogo entre teoria e práxis educativa;

b) a pedagogia da brincadeira;

c) o estudo da infância e a sua educação entre passado e presente;

d) a avaliação formativa de contexto;

e) a formação "reflexiva" dos professores e demais profissionais da educação.

\section{C.M. \& G.S.: Como se deram os vínculos teoria-prática?}

A.B.: Primeiramente é necessário dizer que o modo de conceber esse núcleo distingue todos aqueles que ao longo do tempo realizaram e que atualmente realizam pesquisas em colaboração com os Professores de Pedagogia do atual Departamento de Estudos Humanísticos da Universidade de Pavia (antes Faculdade de Letras e Filosofia), quando compartilham com os profissionais da educação empenhados na prática quotidiana o seu trabalho de pesquisa. A atividade de pesquisa e de reflexão das pessoas que a cada momento se agregaram ao grupo se caracterizou pela estreita conexão entre teoria e práxis educativa. Todos nós fomos profundamente influenciados pelo pensamento deweyano, particularmente pela ideia de que experiências educativas e teorias da educação podem encontrar uma forte conexão em uma concepção da pesquisa como pensamento reflexivo, que nasce da experiência, ou seja, do contato com situações educativas concretas, e as investiga, interroga, e as problematiza, retorna a elas com hipóteses interpretativas e/ou propostas de soluções que recorrem novamente à experiência. Na pesquisa relativa aos fenômenos educativos do passado, essa orientação se traduziu na atenção ao entrelaçamento entre "cos- 
tumes educativos" (BECCHI, 1983; FERRARI, 2010a) e ideias pedagógicas; na pesquisa sobre os fenômenos educativos da atualidade, a mesma orientação nos induziu a enfrentar o estudo dos processos e contextos educativos concretos através de formas de pesquisa empírica de caráter qualitativo. O que acontece realmente nos contextos educativos? Quais fenômenos podem ser observados? Como se desenvolve a vida quotidiana nas situações compartilhadas por adultos e crianças? Como os adultos pensam e realizam a própria tarefa educativa? Através de quais estratégias?

Nos percursos de pesquisa que empreendemos para tentar dar respostas a essas questões procuramos instituir os contextos e as práticas educativas como objeto de reflexão e/ou pôr à prova ideias pedagógicas, realizando propostas educativas inovadoras. Os filtros através dos quais procuramos, a cada novo momento, olhar os fenômenos educativos concretos e que, em diversos casos, nos induziram a elaborar instrumentos de análise inéditos, foram frameworks teóricos utilizados como hipóteses de trabalho a serem postos à prova no confronto com o que observávamos. Outras vezes estabelecemos inovações educativas e, nestes casos, buscamos compreender o significado da inovação, as qualidades, os defeitos, os limites, as sugestões para novas pesquisas. Mas não somente isso. Nesses percursos fomos acompanhados e/ou acompanhamos realidades educativas que desejavam refletir sobre as próprias escolhas e as próprias práticas. Daí nasceu um intercâmbio frutífero que consentiu a nós, pesquisadores, aproximarmo-nos aos fenômenos educativos "por dentro" e consentiu aos educadores problematizar a própria experiência. A ideia propriamente deweyana de uma continuidade entre saber comum e saber científico, que encontra o próprio trait-d'union no pensamento reflexivo, caracteriza ambas as formas de saber e nos sugeriu a plausibilidade de uma cooperação reflexiva entre os pesquisadores profissionais e os educadores, além da necessidade de inventar modos democráticos de fazer pesquisa que consintam um real diálogo de pontos de vista, experiências, problemáticas.

\section{C.M. \& G.S.: A temática da brincadeira foi e continua sendo enfrentada por vocês (ou pelo grupo) com vistas à argumentação teórica e à definição operativa das características de uma pedagogia orientada ao lúdico. Pode- riam comentar a respeito?}

D.S.: Essa temática vem sendo enfrentada em duas direções principais de pesquisa. A primeira trata de esclarecer a natureza da brincadeira e o seu papel no crescimento infantil. Através da reflexão teórica chegou-se a reconhecer a brincadeira como realidade através da qual a criança desenvolve a sua relação com o mundo exterior (os objetos, as pessoas) e interior (as suas vivências emotivas profundas). Enfatizamos particularmente o seu papel nos processos 
de socialização da primeira infância, no sentido tanto da formação de grupos de brincadeira cooperativos entre pares quanto da possibilidade que a brincadeira oferece à criança de apropriar-se dos sistemas simbólicos culturais, tematizando a estreita inter-relação entre "culturas da infância" e culturas do adulto. Através da coleta de dados observados, sempre em circunstâncias ecológicas (crianças que brincam nas suas pré-escolas ou creches), colocamo-nos o problema da observação dos comportamentos lúdicos, da definição das suas diversas manifestações e da sua relação com as competências que os atravessam, chegando a propor metodologias e instrumentos ad hoc.

A segunda direção de pesquisa é relativa à argumentação do sentido e da possibilidade de uma pedagogia da brincadeira, bem como a sua definição em termos operativos. O sentido de uma pedagogia lúdica está ancorado no aprofundamento da natureza evolutiva da brincadeira: já que se pode claramente demonstrar o quanto é crucial o comportamento lúdico para o crescimento e o bem-estar infantil, então não se pode prescindir de considerá-lo uma realidade de referência para a relação educativa, especialmente nas idades relativas à educação infantil e no cotidiano das instituições educativas.

A propósito disso, colocamos em evidência a peculiaridade de uma pesquisa para a definição de uma pedagogia da brincadeira: trata-se de desafiar uma aparente antinomia entre a brincadeira, a sua natureza espontânea, livre, não finalizada, e a educação, entendida como relação projetada para orientar quem é educado em direção a atingir certos objetivos evolutivos pré-definidos.

Aceitar esse desafio significou, antes de mais nada, apontar para âmbitos teóricos diferentes, inclusive não especificamente envolvidos com a brincadeira: às teorias psicanalíticas, adquirindo a ideia de que da brincadeira, dos seus conteúdos, somente a criança pode ser "dona", sob pena de pôr fim à própria brincadeira; ao conceito vigostskiano de "zona de desenvolvimento proximal" e aos seus desenvolvimentos na teoria do tutoring, com a ideia de um envolvimento adulto que estimula níveis de competência potenciais, colocando-os em ato em primeira pessoa, e que defende a motivação à persecução de uma direção, simplificando o percurso, salientando as passagens facilitadoras, contendo as frustrações ligadas ao insucesso.

Entrelaçamos o aprofundamento com o pôr à prova empírica, o que consentiu tanto chegar a modelar com uma certa precisão a atitude e as condutas de um adulto que se relaciona com a brincadeira para promovê-la, quanto verificar sua possibilidade. Esse estilo de ação nós o identificamos como "promoção a partir do interno" e o testamos e modulamos, tendo sempre como referência contextos "ecológicos", ou seja, educadores e professores que brincam com grupos de crianças nas suas escolas e creches. As nossas mais recentes reflexões sobre a "promoção a partir do interno" nos levam a considerar a possibilidade 
de que não se trate de um estilo educativo circunscrivível à brincadeira, mas principalmente de uma ideia mais geral de relação educativa, relativa também à formação dos professores, cujos princípios de base são: aprendizagem entendida como construção compartilhada de significados comuns; troca paritária, baseada na reciprocidade, entre quem educa e quem é educado; promoção de processos de reflexão e de elaboração compartilhados ${ }^{3}$.

\section{C.M. \& G.S.: Como surge o interesse e os estudos sobre história da infância e história da educação no grupo de pesquisa de Pavia?}

M.F.: O interesse por alguns construtos heurísticos que nos levaram a interrogar os documentos do passado e a documentar o presente, com um olhar para o futuro, a partir de específicos casos de estudo, orientou - e orienta - os percursos de pesquisa sobre os fenômenos educativos, entre ontem e hoje, entre ser e dever ser.

Por isso recordo aqui, no início de uma breve reflexão sobre questões de história da infância e de história da educação, com particular referência ao trabalho dos programas pedagógicos da Universidade de Pavia (daquele que agora se chama Departamento de Estudos Humanísticos), o construto chamado "costume educativo" (BECCHI, 1983), que veio à tona nos seminários organizados na Fundação Feltrinelli de Milão por Egle Becchi, nos anos oitenta do séc. XX. Tal construto tem fortes potencialidades heurísticas; ele permite interrogar os acontecimentos educativos do passado a partir de perspectivas que vão além dos recintos disciplinares, não somente relativos à primeira infância, e se conjuga hoje com outros conceitos-chave da reflexão pedagógica do séc. XX. Pense-se, por exemplo, antes de mais nada, naquele "sentimento de infância", ligado aos estudos de Ariès sobre a infância e sobre a vida familiar na sociedade europeia de antigo regime, mas também na ideia de "dispositivo", emersa a partir das análises de Foucault sobre os processos de subjetivação, ou de "prática cultural", no centro de uma vasta reflexão sobre o tema da "aculturação", em que os estudos de Dupront tiveram um papel importante.

Tal ideia acabou depois se enredando com outras pesquisas, com o "culturalismo", com um novo modo de fazer história, de estudar, por exemplo, as práticas da leitura e da escritura (cf., a mero título de exemplo, os estudos de Roger Chartier). Pense-se também nas reflexões de Chervel sobre os modos em que a escola "produz cultura" (CHERVEL, 1998) e constrói as "disciplinas escolares".

As pesquisas relativas aos onipervasivos fenômenos educativos podem e devem, não somente na opinião de quem escreve, configurar-se em ótica diacrô-

3 Remete-se, a mero título de exemplo, a alguns estudos de Bondioli (1989, 1996, 2004a) e Savio (1995a). 
nica e com um olhar para o futuro a partir de abordagens precisas e documentadas que vão além dos recintos disciplinares e no diálogo contínuo com profissionais e especialistas. Isso exige, como já salientava Ariès, a capacidade de analisar fontes diversas, "textos" que não são feitos somente de palavras, úteis para se interrogar sobre atitudes culturais, entre passado e presente.

Em muitos lugares hoje se enfatiza que estudar os traços da "materialidade educativa" (outro construto importante do séc. XX), o modo em que a "lição das coisas", frequentemente de maneira latente, permeia os ambientes em que crescem os cidadãos, seja uma tarefa importante que nos aguarda no nosso mundo globalizado em que novos contextos educativos e novas mídias estão redefinindo os mecanismos de transmissão dos conhecimentos, as modalidades de construção dos saberes e os contextos educativos. Hoje um amplo debate sugere que devemos prestar mais atenção não somente à "cultura para a infância", mas também à "cultura $d a$ infância", aos modos em que as crianças, para usar as palavras de Corsaro (2003 [1997]), operam uma "reelaboração interpretativa" da proposta dos adultos e constroem compartilhando novos saberes. Também por isso devemos interrogar fontes de várias tipologias não somente em relação ao passado, devemos estudar o que acontece nos contextos educativos e no quotidiano.

C.M. \& G.S.: Desde os anos noventa, tendo começado com Egle Becchi, Anna Bondioli, Mônica Ferrari e, mais recentemente, Donatella Savio, além de outros pesquisadores, o grupo de Pavia tem trabalhado com a temática da avaliação de contextos educativos na interface com a qualidade educativa. Como surgiu e se desenvolveu esse interesse?

M.F.: O tema da avaliação educativa é de grande interesse do ponto de vista pedagógico e político; ele exprime e ao mesmo tempo exaspera o aspecto pragmático da pedagogia. Os instrumentos de avaliação dos contextos educativos, como todos os "dispositivos" pedagógicos, podem orientar as escolhas em termos de política formativa e, sobretudo, ratificando o que afirma Bruner no seu livro dedicado à cultura da educação (BRUNER, 1997 [1996]), ajudar os políticos que decidem, bem como os profissionais da educação, a crescer em consciência acerca das questões e das antinomias que caracterizam os fenômenos educativos.

Os instrumentos de avaliação da qualidade dos contextos educativos adaptados à situação italiana e/ou construídos ex novo ao longo dos anos, por pesquisadores ligados, de várias maneiras, aos Programas pedagógicos da Faculdade de Letras e Filosofia da Universidade de Pavia (e ao atual Departamento de Estudos Humanísticos), são numerosos. Alguns são relativos aos contextos educativos para a pequena infância. Pense-se na SOVASI [Scala per l'Osservazione e la Valutazione della Scuola dell'Infanzia] (HARMS; CLIFFORD, 1994 [1980]) ou na SVANI 
[Scala per la Valutazione dell'Asilo Nido] (HARMS; CRYER; CLIFFORD, 1992 [1990]), traduzidos e adaptados à situação italiana no decorrer do desenvolvimento das teses de doutorado de Monica Ferrari, Paola Livraghi, Antonio Gariboldi. Pense-se também na ASEI [Autovalutazione dei Servizi Educativi per l'Infanzia] (DARDER; MESTRES, 2000 [1994]), traduzido e adaptado à situação italiana no desenvolvimento da tese de doutorado de Maria Paola Gusmini. Já o ISQUEN [Indicatori e Scala di Valutazione della Qualità Educativa del Nido] (BECCHI; BONDIOLI; FERRARI, 1999) e a AVSI [AutoValutazione della Scuola dell'Infanzia] (BONDIOLI et al., 2001 e 2008) são instrumentos construídos compartilhadamente e testados em campo em relação ao contexto italiano, assim como o SASI-S [Strumento di Autovalutazione della Scuola (Infanzia - Secondaria)] (FERRARI; PITTURELLI, 2008) ou o DAVOPSI [Dispositivo di Analisi e Valutazione dell'Organizzazione Pedagogica della Scuola dell'Infanzia] (BONDIOLI; NIGITO, 2008). Não se negligenciou a reflexão sobre a qualidade dos projetos pedagógicos das creches (BECCHI; BONDIOLI; FERRARI, 2002) e sobre as "Ideias-guia da creche" (Idee guida del nido d'infanzia. BECCHI et al., 2002).

Os pesquisadores "paveses" também trabalharam no estabelecimento de um particular método de observação do quotidiano dos contextos educativos, que culminou na publicação, em 1993, de uma primeira série de estudos; e depois sucessivamente aplicado em contextos bastante diversificados, desde a creche a outras etapas escolares. (BONDIOLI, 2000, 2002a, 2007; FERRARI, 2003).

Alguns instrumentos foram preparados para outras ordens e graus de escola ou são relativos a problemáticas particulares (cf. SVALSI [Scala di Valutazione delle Abilità Ludico-Simboliche Infantili]: BONDIOLI; SAVIO, 1994a; ERVIS [Elementi per Rilevare e Valutare l'Integrazione Scolastica]: BONDIOLI et al., 2009; SAVIO, 2011; SAPIENSSII [Strumento per l'Autovalutazione dei Processi Interculturali in Educazione nella Scuola Secondaria di Secondo Grado]: FERRARI; LEDDA, 2012). Alguns são "transversais" e não concernem somente um particular contexto escolar, porque visam principalmente a construir um léxico comum entre professores de diversos níveis e graus da escola (cf. DARDER; LÓPEZ, 1989-1998; DARDER; MESTRES, 2000 [1994]; FERRARI, 2001; FERRARI; PITTURELLI, 2008). Todos voltados a ajudar os profissionais da educação a refletir sobre o fazer a partir de seu trabalho nos contextos educativos; em particular um entre eles refere-se especificamente ao tema da avaliação da profissionalidade dos docentes (cf. SABBATINI, 2009-2010).

Tais dispositivos de análise da qualidade educativa dos contextos educativos, não obstante a diversidade das abordagens (mais ou menos "transversais") e da estrutura (em alguns casos, por exemplo, são escalas ordinais, em outros questionários), são caracterizados por uma perspectiva de pesquisa que atribui importância à intersubjetividade da avaliação (com base em experiências do- 
cumentadas e instrumentos confiáveis) e ainda a todos os sujeitos envolvidos. Trata-se de um "modelo" de avaliação "formativa" que foi sendo afinado ao longo dos anos e se baseia na ideia de que o que deveria conduzir a uma mudança para melhor é uma decisão negociada entre os atores sociais envolvidos no processo, fruto de um exercício de compartilhamento e de crescimento em consciência: um processo "constitutivamente" intercultural.

Uma ideia comum a esse "grupo", tão variado, de pesquisadores e de especialistas que colaboraram, de várias maneiras, ao longo dos anos, com os Programas pedagógicos da Universidade pavese: o fato de que é essencial partir de um compartilhamento com os professores e outros profissionais acerca da experiência avaliativa até se chegar a uma "desconstrução" do dispositivo de análise proposto. Somente um real envolvimento de todos os atores no processo da avaliação pode conduzir a uma mudança da qualidade de vida de uma organização humana, porque se trata sempre, não somente na opinião de quem escreve, de uma mudança de mentalidade, da mudança de uma atitude cultural.

\section{C.M. \& G.S.: Outra frente de pesquisa que distingue o trabalho do} grupo se relaciona à formação dos professores e outros profissionais das instituições educativas para a infância. Como esse processo se relaciona àquele da avaliação de contexto na abordagem do grupo pavese?

A.B.: A avaliação de contexto, na nossa abordagem, tem um caráter nitidamente formativo. Parte da ideia de que refletir com os professores sobre as práticas educativas seja um modo de fazer pesquisa que promove consciência tanto no pesquisador profissional quanto no profissional da escola. Educare la professionalità degli operatori per l'infanzia ("Educar a profissionalidade dos educadores para a infância”) é o título de um livro, organizado por Anna Bondioli e Monica Ferrari (2004b), no qual questiona-se sobre a especificidade do trabalho de quem tem responsabilidades educativas em relação às crianças pequenas $\mathrm{e}$ sobre os modos de qualificá-los e valorizá-los. Uma profissionalidade que não se adquire de uma vez por todas, mas que cresce e se afina no tempo, graças à prática de operações complexas dirigidas a conhecer a criança e apoiá-la no seu desenvolvimento, a projetar conscientemente e coletivamente percursos e experiências educativas, a refletir sobre tais experiências à luz de seus resultados, a reprojetá-las novamente com base em tal reflexão. Maturamos a consciência de que a formação dos profissionais para a infância - sobretudo a formação "em serviço" - deveria ter as características de abertura, tomada de consciência, empowerment. Abertura no sentido de acolhida atenta das manifestações infantis; tomada de consciência no sentido de promover responsavelmente o crescimento através de percursos projetados e verificados; empowerment no sentido de apoio e valorização das capacidades profissionais e da experiência, maturadas no 
curso do trabalho. Nestes últimos anos algumas de nós - particularmente Anna Bondioli e Donatella Savio, juntamente com alguns colaboradores - realizaram percursos de formação, dirigidos a grupos de professores de pré-escolas e creches, caracterizados por estratégias peculiares que chamamos de "promoção a partir do interior". Trata-se de uma abordagem que atribui ao formador um papel peculiar, o de apoiar o processo reflexivo, em grupos de operadores, a partir das ideias destes e das suas experiências, estimulando a explicitação de convicções educativas e da motivação das práticas utilizadas com as crianças, promovendo o debate, procurando, com o concurso dos diversos participantes, dar um "sentido" ao trabalho por eles desenvolvido e projetar, juntamente com eles, inovações conscientes. Esta abordagem foi utilizada nas experiências de avaliação formativa que caracterizaram o trabalho desenvolvido nos últimos anos com coletivos de creches e pré-escolas (cf. BONDIOLI; SAVIO, 2010; SAVIO, 2011) e foi, ela mesma, tomada como objeto de investigação em pesquisas voltadas a estudar o papel de facilitador desenvolvido pelo formador e as peculiares estratégias de que se vale para a promoção a partir do interno.

\section{PARTE II. Os percursos de formação e de pesquisa individuais dos membros atuais do grupo: Anna Bondioli, Monica Ferrari, Dona- tella Savio}

C.M. $\&$ G.S.: Nesta parte são narrados os percursos individuais de cada pesquisadora. Podemos observar, numa trama de histórias, além da dimensão pessoal, como (quando possível) o percurso individual se entrelaça com o do grupo, e também como por meio desta operação da memória refletida foram possíveis reconstruir os encontros, as pessoas, as instituições educativas e as suas administrações, que marcaram tanto os percursos individuais quanto os do grupo.

\section{Anna Bondioli}

\section{mica? \\ C.M. \& G.S.: Anna, o que destacaria acerca da sua formação acadê-}

A.B.: Fiz o curso de estudos de Filosofia (curso quadrienal), na Universidade de Pavia, concluído com monografia em Pedagogia (orientada por Renato Tisato) com o título de Método psicológico-heurístico e método lógico-sistemático: as hipóteses de Dewey e Bruner. Nesse trabalho, partindo de um exame dos conceitos deweyanos de experiência e pensamento reflexivo, apre- 
sentei os pressupostos teóricos do ativismo pedagógico, pondo em evidência a problemática das formas de aquisição do saber de tipo down-top (aprendizagem como pesquisa). A discussão levada adiante no trabalho da monografia levava em consideração o clima cultural e político da Itália no princípio dos anos setenta, período no qual, após a formatura, eu havia iniciado uma colaboração com a cátedra de Pedagogia na Universidade de Pavia, como "responsável por atividades de apoio didático". Um clima cultural e político no qual se desenvolveram os meus interesses pedagógicos.

Os anos setenta foram, realmente, na Itália, um período de ebulição no âmbito da educação: sentia-se a necessidade de uma renovação das instituições escolares, tanto do ponto de vista estrutural quanto do ponto de vista didático. Desejava-se uma escola mais ativa, mais aberta ao social, mais colaborativa. São os anos dos Decretos Delegados com os quais foram adotadas formas institucionalizadas de participação (dos pais e dos professores) em todos os níveis escolares ${ }^{4}$. A crítica à "escola tradicional" era um leit motiv do debate pedagógico daqueles anos, sobretudo porque ela parecia incapaz de realmente oferecer a todos oportunidades iguais de crescimento e formação. Desenvolvia-se uma crítica pesada à "seleção", que atingia os filhos das classes sociais mais frágeis e menos aculturadas, às quais a escola parecia não oferecer oportunidades de resgate ${ }^{5}$.

É nesse clima que iniciei a colaboração com Egle Becchi - recém-chegada à Universidade de Pavia. Egle Becchi naqueles anos observava com atenção e defendia experiências inovadoras e, sobretudo, inseria-se entre aqueles que desejavam não somente a renovação da escola, mas também a discussão acerca da inovação, de acordo com uma lição segundo a qual "fazer pesquisa" na escola e "experimentar" são operações não somente cientificamente relevantes, mas também necessárias para adquirir consciência do "fazer educativo". Tratava-se de ideias muito novas no ambiente acadêmico de então. Sobretudo era nova a ideia de que entre teoria da educação e práxis educativa deveria haver um contínuo feedback e que a pesquisa pedagógica não podia prescindir de interrogar a experiência, refletir sobre ela e retornar à teoria para modificá-la e/ou enriquecê-la.

4 É a partir dos anos setenta que ganha força na Itália a ideia de que as famílias têm o direito, mas também o dever, de participar da vida da escola. Os Decretos Delegados dos anos setenta (especialmente D.P.R. [Decreto do Presidente da República, N.T.] n n 416, de 1974) sancionavam tal participação através da instituição de representações das famílias - os Órgãos Colegiados - com funções consultivas e deliberativas.

5 Tiveram importância particular, naqueles anos, a pesquisa desenvolvida por dois sociólogos sobre o caráter classista da escola e da categoria dos professores italianos (BARBAGLI; DEI, 1969), a experiência e as reflexões de Don Milani e a difusão de ensaios de sociólogos e filósofos franceses, nos quais se defendia que a escola desenvolvia uma função de reprodução da ordem social. (ALTHUSSER, 1970; BOURDIEU; PASSERON, 1970). 


\section{C.M. \& G.S.: E como surge nessa trajetória o interesse pelos contextos educativos para a infância?}

A.B.: Nos anos setenta, na Itália, abrem-se novas perspectivas também no que diz respeito às instituições para a infância. Em 1971 é promulgada a lei nacional 1044, que modifica radicalmente a estrutura das instituições pré-existentes (ex $\mathrm{ONMI}^{6}$ ) para a faixa 0-3 anos. A creche não é mais concebida como uma instituição somente "de custódia", mas como uma instituição educativa. Nascem múltiplas iniciativas a partir dessa data. Os municípios se aparelham para apoiar tais instituições e, no plano pedagógico, constitui-se em nível nacional um grupo, formado por operadores, coordenadores pedagógicos, administradores, pedagogos e docentes universitários interessados nas problemáticas da infância (Gruppo Nazionale Nidi Infanzia ${ }^{7}$ ). Figura de destaque dessa renovação é Loris Malaguzzi. Desde o início dos anos oitenta sigo com interesse, como membro ativo, os trabalhos dessa associação e inicio uma reflexão que se desenvolverá em diversas direções sobre a pedagogia para a infância. Tendo-me tornado, nesse meio tempo, pesquisadora, colaborei com Egle Becchi em duas pesquisas solicitadas pela Administração Provincial de Pavia sobre as instituições para a infância desse território; a primeira relativa à situação e aos problemas das creches (BECCHI; BONDIOLI, 1983), a segunda das pré-escolas (BECCHI; BONDIOLI, 1984). Dali tem início um interesse preciso pelos processos de socialização da primeira infância nos contextos extradomésticos (creches e pré-escolas), que desembocará, em 1987, na redação, juntamente com Susanna Mantovani, do Manuale critico dell'asilo nido (Manual crítico da creche) e, mais tarde, na colaboração no Manuale della scuola del bambino dai tre ai sei anni (Manual da escola da criança dos três aos seis anos), organizado por Egle Becchi.

\section{C.M. \& G.S.: Anna, e como surgiu seu interesse por uma pedagogia da brincadeira?}

A.B.: Comecei a me ocupar da brincadeira infantil e a refletir sobre as peculiaridades de uma pedagogia lúdica em relação às crianças de 0 a 6 anos,

6 ONMI - Opera Nazionale Maternità e Infanzia (“Obra Nacional Maternidade e Infância”), foi um ente assistencial fundado em 1925 pelo governo fascista italiano; durou até 1975 [N.T.].

7 Nascido em 1980, por iniciativa de Loris Malaguzzi, o Gruppo Nazionale Nidi Infanzia é uma associação que quer oferecer oportunidades de encontro e discussão entre pessoas que atuam no setor da educação da primeira infância, em lugares diferentes e em diversas situações profissionais, em torno dos temas da vida e da condição social das crianças pequenas, do cuidado e da educação na primeira infancia, da qualidade e das perspectivas das escolas e das instituições para a infância. Atualmente reune educadoras, professoras e operadores das creches, das pré-escolas e das outras instituições para a infância, administradores e responsáveis pelas instituições, coordenadores, pedagogos, pesquisadores e docentes universitários, atuantes em diversas cidades italianas. 
nesse mesmo período. Alguns estímulos foram para mim significativos em tal sentido: as memórias da minha infância, o encontro com a psicologia do inconsciente $^{8}$ e o contato com Greta Fein, estudiosa da Universidade de Maryland.

Quando criança tive um adulto que brincou muito comigo, a minha avó paterna. Recordo longas tardes de inverno passadas no seu quarto a desenhar, ouvir histórias e, principalmente, a criar situações imaginárias nas quais minha avó, atendendo a meu pedido, interpretava os papéis de "professora", "médica" ou "negociante", colocando-se à minha disposição e em sintonia com os meus desejos. Na primavera e no verão eu brincava no pátio de casa com meninos e meninas de diversas idades, um pequeno "bando" com o qual, ao lado de brincadeiras de faz de conta, tipo cowboys e índios, eu ia aprendendo e me exercitando em típicas brincadeiras infantis: amarelinha, pega-pega, esconde-esconde, etc. Eram brincadeiras envolventes e excitantes, nas quais eu me sentia "colocada à prova", desejava vencer, e aprendia a conhecer não somente as dinâmicas de grupo - amigos-inimigos, inclusão-discriminação, macho-fêmea, etc. -, mas também as características de personalidades dos colegas, mais ou menos generosos, criativos ou solidários. Tanto as brincadeiras com minha avó quanto aquelas com os colegas, inclusive meu irmão, quatro anos mais novo, constituíram para mim uma espécie de escola na qual eu exercitava a imaginação como expressão da subjetividade e do pensamento criativo e na qual aprendi, nos limites de um microcosmo adequado a mim, as regras da "brincadeira social". Meu pai, além de professor, foi um apreciado artista, que compartilhava com a família descobertas, incertezas, paixões. Desde os anos da infância tive, através do seu vívido exemplo, a sensação de que havia uma analogia entre brincadeira e arte e que a experiência lúdica que eu vivia nas minhas brincadeiras não estava tão longe da experiência que meu pai vivia quando pintava ou desenhava. Isso tornou nossa relação especial, baseada em uma recíproca empatia. Creio que essas experiências positivas da minha infância tenham contribuído para que eu não perdesse, já adulta, o contato com o mundo infantil, que eu recuperasse a capacidade de olhar o mundo "com os olhos das crianças", que eu experimentasse novamente sensações adormecidas (medos, entusiasmos, descobertas). A descoberta do mundo infantil através das leituras dos clássicos da pedagogia e das pesquisas mais atualizadas foi para mim um "reencontro", uma espécie de autoanálise. Para isso contribuiu também a segunda das experiências a que eu acenava: o encontro com a psicologia do inconsciente, na forma de um curso

8 O termo original utilizado por Anna Bondioli é "psicologia del profondo", termo introduzido por Eugen Bleuler para referir-se à existência de mecanismos e dinâmicas psíquicas inconscientes, que são fundamentais para explicar o comportamento e o psiquismo humano (psicologia dinâmica). [N.R.T.] 
de dois anos de "Formação psicodinâmica para educadores das instituições para a infância", na Universidade de Torino, no qual desenvolvi uma experiência de infant observation sob a supervisão de Anna Alvarez e Isca Wittenberg, da Tavistock Clinic de Londres. Já há alguns anos eu havia iniciado uma pesquisa profunda sobre o significado da brincadeira nos anos da infância, encontrando nos textos de alguns clássicos da psicanálise - Sigmund e Anna Freud, Melanie Klein, Donald Winnicott - inspirações interessantes para formular uma hipótese de uma "pedagogia" da brincadeira, mas foram as supervisões sobre as observações de uma dupla mãe-criança, desenvolvidas por dois anos consecutivos, em cadência semanal, que me permitiram reconhecer de maneira mais vívida e mais envolvente a alteridade da criança em relação ao adulto, a sua proximidade ao inconsciente, as manifestações da sua afetividade e, ao mesmo tempo, reconhecer as "vivências" dos adultos - no caso específico da mãe e dos familiares - em relação à criança. Dessa experiência extraí a convicção de que não se pode falar de pedagogia da primeira infância sem levar em conta a subjetividade da criança, da sua natureza pulsional, e, ao mesmo tempo, que não existe uma criança "em si e por si", mas sempre uma criança em relação com um adulto que a acompanha e lhe restitui uma imagem de si. Assim o tema da brincadeira se entrelaçou ao tema do papel do adulto e ambos confluíram na tentativa de definir uma "pedagogia de perspectiva lúdica" para a infância. (BONDIOLI, 1989, 1990, 1996).

De fato, estudando a literatura sobre o tema eu me havia dado conta de algumas carências: a brincadeira era considerada um fenômeno "natural" da infância e não uma experiência a ser apoiada e promovida; o papel do adulto na brincadeira era negligenciado como objeto de pesquisa; ao considerar os efeitos educativos da experiência lúdica eram levados em consideração principalmente os aspectos cognitivos e sociais, mas muito pouco os emotivo-afetivos.

O encontro com Greta Fein, que em 1981 havia publicado um importante review sobre o "estado da arte" da pesquisa sobre a brincadeira infantil (FEIN, 1981), permitiu-me entrar em contato com um filão de pesquisa no qual o concreto brincar das crianças era estudado segundo as metodologias da pesquisa empírica, enriquecendo assim a possibilidade de "pôr à prova" hipóteses teóricas estudadas até aquele momento, e verificar os efeitos de propostas educativas de caráter lúdico. Inicia aqui a colaboração com Donatella Savio, empenhada em uma tese de doutorado sobre a promoção do jogo simbólico infantil. Juntas organizamos um instrumento, a SVALSI (Scala di Valutazione delle Abilità Simboliche Infantili - "Escala de Avaliação das Habilidades Simbólicas Infantis") (BONDIOLI; SAVIO, 1994a), útil tanto como instrumento de pesquisa quanto como "guia" para formar os professores, educadores infantis, a "agir na área potencial de desenvolvimento lúdico" de grupos de crianças. O desafio 
maior, nos estudos realizados sob essa perspectiva, era o de estabelecer uma proposta formativa específica para a idade infantil, baseada no reconhecimento da importância da brincadeira e das condutas simbólicas ("fazer de conta", narração fantástica, dramatização lúdica) na vida da criança e no seu percurso de crescimento, como manifestação espontânea de alegria e de bem-estar, e voltada a valorizar e a promover suas formas mais sublimadas e socializadas sem desnaturar suas características de espontaneidade, alegria, envolvimento. Uma proposta formativa que chamei de "promoção a partir do interno" para salientar o peculiar papel desempenhado nela pelo adulto e as funções a ele atribuídas, de apoio e desenvolvimento da atividade lúdico-simbólica infantil. (BONDIOLI, 2001). A proposta, colocada à prova em alguns estudos (BONDIOLI; SAVIO, 1994b), foi sucessivamente estendida também à narração infantil. (cf. BONDIOLI, 2004a).

\section{C.M. \& G.S.: O que poderia acrescentar quanto à abordagem de vocês acerca dos temas qualidade e avaliação formativa de contexto?}

A.B.: No princípio dos anos noventa, na Itália, começa-se, de fato, a falar de avaliação da escola, um tema absolutamente novo no panorama italiano. No âmbito das instituições para a infância o termo que melhor se harmoniza com o da avaliação é o da qualidade. Como garantir serviços de qualidade? Quais condições e parâmetros caracterizam a qualidade? Quem é chamado a "fazer" a qualidade? E quem a fiscalizá-la? Tratava-se de um problema ao mesmo tempo político e pedagógico que levou o grupo pavese a estudar, refletir e fazer pesquisas sobre o tema, juntamente com alguns doutorandos que em seu trabalho de tese estavam se ocupando desse argumento. No início dos anos 1990, Monica Ferrari, Donatella Savio, Antonio Gariboldi, Paola Livraghi, Maria Paola Gusmini, Elena Mignosi realizaram seus trabalhos de doutorado e, tanto no que se refere aos posicionamentos quanto às temáticas, seus estudos se colocaram no filão daqueles até então desenvolvidos por Egle Becchi e por mim. Daqueles anos destaco a elaboração de um instrumento, "a jornada educativa", para observar, analisar e avaliar o que acontece em uma sala de aula durante as horas transcorridas na escola. $\mathrm{O}$ instrumento, organizado em uma primeira versão em uma pesquisa voltada a captar a fisionomia de turmas da pré-escola (cf. Insegnamenti pedagogici del Dipartimento di Filosofia dell'Università di Pavia, 1993), foi sucessivamente utilizado como dispositivo para refletir, junto com educadores e professores, sobre o que acontece concretamente nas salas de aula e sobre as ideias educativas que orientam a prática pedagógica. A análise que o instrumento consente, seja como dispositivo heurístico seja como estímulo à reflexão para os professores, deriva de um posicionamento teórico baseado no construto cha- 
mado "pedagogia latente" (BONDIOLI, 2000; BECCHI, 2005), sobre o qual tive oportunidade de refletir, principalmente ao longo das sucessivas redações do instrumento ${ }^{10}$. (BONDIOLI, 2000, 2002a; FERRARI, 2003; FERRARI, V., 2006-2007). A ideia de que nem tudo o que tem lugar nos contextos educativos seja fruto de uma intencionalidade consciente por parte dos professores e que, não obstante esse fato, produza efeitos potentes de modelagem sobre as crianças e sobre os alunos, foi um leit motiv que orientou fortemente a minha pesquisa e o modo de conceber a formação de educadores e professores. Quando Egle Becchi, Monica Ferrari e eu começamos a nos ocupar de avaliação, a ideia de que juntamente com as práticas educativas e os contextos concretos deveriam ser avaliadas também as ideias de educadores e professores, e que a avaliação deveria partir de uma explicitação de tais convicções, frequentemente inconscientes, configurou-se como uma "ideia guia" que orientou a pesquisa sucessiva.

O grupo, desde o começo, orientou-se no sentido de elaborar - e realizar - uma ideia de avaliação formativa e participativa (BONDIOLI; FERRARI, 2000, 2004a e 2004b; BONDIOLI, 2002b; BONDIOLI; SAVIO, 2010), que consentisse a grupos de educadores ou professores, sob a orientação de um formador, refletir sobre a realidade educativa na qual atuam, com o fim de se tornar mais conscientes sobre a organização pedagógica e as práticas educativas realizadas, além das próprias convicções, e chegar, por essa via, a projetar ações de melhorias. Participação e reflexão, portanto, como palavras-chave de uma abordagem à avaliação, baseada no debate e na negociação interna de um grupo de trabalho que, através do próprio processo avaliativo, torna-se consciente das próprias práticas e das próprias convicções e, de maneira mais responsável, age para uma melhoria. Nesse modelo, que chamamos de "qualidade negociada" (BONDIOLI; GHEDINI, 2000; BONDIOLI, 2002b) e de "avaliação formativa" (BONDIOLI; FERRARI, 2004b), desempenham papel fundamental os instrumentos adotados. Os instrumentos são "guias para os olhos", que orientam e

9 Por pedagogia latente se entende uma pedagogia "implícita, não tanto imputável à improvisação ou ao acaso quanto à aceitação acrítica de práticas habituais, settings pré-constituídos, modalidades operativas usuais". (cf. BONDIOLI, 1993, p. 2). Trata-se de uma pedagogia inscrita na disposição dos espaços e dos móveis e decoração, na sequência das situações oferecidas, nas "normas" não discutidas que regulam a vida quotidiana, que pode ser definida como "pedagogia latente", enquanto não sujeita a deliberação consciente. (BONDIOLI, 1993, p. 2).

$10 \mathrm{O}$ instrumento da "jornada educativa" foi aplicado, com algumas variantes, a realidades educativas diversificadas, desde a creche (cf. NIGITO, 2002; GALDABINO, 2002; BONDIOLI, 2004b), à pré-escola (cf. Insegnamenti pedagogici del Dipartimento di Filosofia dell'Università di Pavia, 1993; BONDIOLI; FERRARI, 1998; BECCHI; BONDIOLI, 1997; BONDIOLI, 2004b; FERRARI, V., 2006-2007), ao ensino fundamental (BONDIOLI et al., 2000; FERRARI, 2002; FERRARI, V., 2006-2007), ao ensino secundário (cf. FERRARI, 2003). Foi utilizado na formação dos professores do ensino secundário nos cursos de especialização instituídos na Universidade de Pavia. 
dirigem a observação e a autoanálise e estimulam o processo reflexivo. É por esse motivo que o grupo se empenhou, desde os anos noventa, a traduzir e adaptar à realidade italiana instrumentos já elaborados: SVANI (HARMS; CRYER; CLIFFORD, 1992 [1990]), SOVASI (HARMS; CLIFFORD, 1994 [1980]), QUAFES (DARDER; LÓPEZ, 1998 [1989]), ASEI (DARDER; MESTRES, 2000 [1994]), bem como a elaborar novos: ISQUEN (BECCHI; BONDIOLI; FERRARI, 1999), AVSI (BONDIOLI et al., 2001; nova edição 2008), DAVOPSI (BONDIOLI, 2008), SASI-S (FERRARI; PITTURELLI, 2008), Lo strumento del nido ludico ("O instrumento da creche lúdica", SAVIO, 2011).

\section{C.M. \& G.S.: Seria interessante compreender a ideia da "promoção a partir do interno" segundo a abordagem "pavese". Poderia nos falar sobre isso?}

$A . B .:$ Se relaciona à outra função essencial no processo avaliativo, que exige do formador-avaliador: apoiar e promover, no processo de avaliação, o processo de explicitação, negociação e reflexão internamente ao grupo dos participantes. Nos últimos anos, trabalhando em colaboração com Donatella Savio, foi se delineando com maior clareza uma ideia já tematizada, relativa a uma pedagogia da infância (BONDIOLI, 1996; BONDIOLI, 2004c; BONDIOLI; SAVIO, 2007) que podia ser transferida à formação dos profissionais da educação, a ideia da "promoção a partir do interno". A ideia de que a tarefa do formador - seja em processos de formação reflexiva seja naqueles de avaliação formativa - não é a de ensinar-instruir, mas de facilitar processos de crescimento e de autoanálise, mediante estratégias calcadas na maiêutica. (BONDIOLI; SAVIO, 2008 e 2010).

Para concluir, repensando no meu inteiro percurso formativo e profissional, nas experiências nos diversos âmbitos que investiguei, da brincadeira à avaliação, da pedagogia para a infância à formação dos profissionais da educação, reconfirmo que a atitude de fundo que animou todas essas experiências, e que pude compartilhar, quando possível, com os colegas do grupo de trabalho, foi a da proposta (modalidades inovadoras de pensar a educação infantil e a formação dos profissionais), inspirada por conviçcões democráticas e sustentada pela vontade de colocá-la à prova, submetendo-a a formas rigorosas de investigação. É este o significado que tem para mim "fazer pesquisa" no âmbito da educação e que creio tenha caracterizado até hoje o meu trabalho de pedagoga: entrar em contato com situações educativas concretas, mergulhar nelas para colher suas peculiaridades, pôr-se a serviço dos profissionais da escola, oferecendo-lhes a própria competência, elaborar instrumentos e/ou propostas, das quais se deve verificar a plausibilidade, a validade, a eficácia, refletir, enfim, sobre todo o processo com o fim de extrair significados que por sua vez são submetidos a 
um processo de verificação e validação consensual (por parte dos participantes e por parte da comunidade científica). Não posso deixar de concluir que se trata de um trabalho ao mesmo tempo criativo, rigoroso, cooperativo, um trabalho de satisfação, mas também de responsabilidade, que senti - e sinto - como parte integrante da minha vida.

\section{Monica Ferrari}

\section{C.M. \& G.S.: Monica, poderia comentar sobre os pontos marcantes de seu itinerário cultural?}

M.F.: As perguntas feitas a Anna Bondioli, a Donatella Savio e a mim me induzem a refletir sobre o meu passado, desde antes que eu me inscrevesse no curso de graduação em Filosofia na Faculdade de Letras e Filosofia da Universidade de Pavia, e a repensar algumas das razões que estão na base das minhas escolhas profissionais. Minha avó paterna era uma professora da escola fundamental, apaixonada por seu trabalho. Sem dúvida, foi graças a ela que se acendeu em mim uma certa curiosidade cultural: me levou pela mão nos primeiros passos em direção à identificação de um "método de estudo" pessoal e de uma busca de respostas ao meu desejo de saber mais; facilitou o meu percurso de aprendizagem, compartilhando-o comigo, dia após dia, nos meus primeiros anos de frequência à escola primária. No geral, tive muita sorte: na minha família há um forte interesse pelas profissões que têm a ver com os cuidados e as relações. Meu pai, médico, me ensinou - e me ensina-a observação das coisas, dos ambientes, das pessoas, a partir dos fatos quotidianos, dia após dia, e bem melhor do que eu domina os saberes do saber ouvir. Minha mãe cultiva o diálogo no mundo dos afetos; tantos amigos, mesmo mais velhos do que eu, alguns professores, foram e são parte da minha "família" e, com eles, construímos um "léxico familiar" que respeita as pessoas; graças a eles aprendi a cultivar amizades intergeracionais.

Frequentei a escola fundamental, a escola média, o liceu clássico em Cremona, uma cidade tranquila que amo, na qual o estilo de vida me permitiu (e me permite) momentos de concentração e de reflexão: no último ano do liceu maturei a convicção de que os estudos filosóficos me permitiriam melhor compreender categorias conceituais e construtos heurísticos úteis para decodificar fenômenos culturais complexos, do passado e do presente. Por isso me inscrevi, no começo dos anos oitenta, no curso de Graduação em Filosofia na Universidade de Pavia. Passei na prova de admissão ao Collegio Ghislieri de Pavia, do qual fui aluna durante todos os anos de frequência à Universidade, que 
foram ricos de sugestões e estímulos, também graças a esta instituição, a qual devo a oportunidade de ter realizado - e de realizar ainda hoje - seminários e congressos. Muitas foram as pessoas que conheci: docentes, colegas de curso e do Colégio, estes últimos inscritos em diferentes cursos de graduação. Com muitos deles pude, naqueles anos, debater livremente.

Uma virada determinante no meu itinerário de crescimento profissional (e humano) aconteceu, com certeza, no final do curso de graduação em Filosofia na Universidade de Pavia. Chegara a hora de escolher o tema de uma monografia de final de curso: eu tinha a ambição de trabalhar com fontes pouco trabalhadas e de aprender a fazer pesquisa, dando uma contribuição, mesmo que mínima, de novidade, em relação a questões urgentes em uma certa comunidade científica que eu definiria, em sentido lato, "humanística". Eram os anos em que eram publicados estudos e pesquisas sobre o tema da história das mentalidades. Em 1974 Jacques Le Goff e Pierre Nora publicavam em Paris Faire de l'histoire, e em 1979, organizado por Jacques Le Goff, Fare Storia, sai na Itália. Fascinava-me então (e continua a fascinar-me) o estudo das atitudes mentais do passado e dos dispositivos formativos latentes que as orientam, dos quais temos mais ou menos consciência, no curso da nossa existência. A descoberta da importância do conceito de "sentimento" coletivo, devida à leitura do texto de Ariès de 1960, conjugava-se para mim naqueles anos com outras reflexões que me ajudavam antes de mais nada a compreender situações que eu tinha vivido diretamente, como aluna de diversas instituições e como pessoa, na minha existência quotidiana. Os cursos que eu estava frequentando na Universidade me estimulavam a fazer outras leituras sempre mais direcionadas: ao estudo dos textos dos "Annalistas" somava-se o interesse por algumas das obras de Michel Foucault e de Carlo Ginzburg. O vivo debate cultural que se exprimia naqueles anos em congressos realizados pelos docentes da Universidade pavese, entre Pavia e Milão (recordo, por exemplo, os seminários organizados por Egle Becchi na Fundação Feltrinelli, sobre o importante construto heurístico chamado "costume educativo", cf. BECCHI, 1983), incentivaram-me a trabalhar com fontes inéditas e pouco trabalhadas, principalmente para aprender uma metodologia de pesquisa capaz de fazer emergir os traços das práticas pedagógicas explícitas e/ou latentes, entre ser e dever ser. Graças à discussão com alguns dos meus professores (em particular com Egle Becchi, que se tornou minha orientadora, enquanto Franco Alessio e Fiorella De Michelis foram os co-orientadores), escolhi o tema da minha monografia de final de curso, defendida em 1985, cujo título era La pedagogia del sovrano: modelli, curriculum e pratica formativa nell'educazione infantile di Luigi XIII e Luigi XIV ("A pedagogia do soberano: modelos, curriculum e prática formativa na educação infantil de Luís XIII e Luís XIV"). Tive assim a oportunidade de trabalhar com o Journal manuscrito 
do protomédico de Luís XIII, Jean Heroard (Madeleine Foisil publicaria, quatro anos mais tarde, em 1989, uma transcrição, completa para alguns dos primeiros anos de vida do menino que viraria rei). Além disso, era necessário encontrar outras fontes, reconstruir o debate sobre a formação do soberano, para compreender os modos e as formas em que se exprime o mecanismo pedagógico de que Heroard é um dos protagonistas. Naquela ocasião comecei a estudar o gênero literário do Institutio principis, com particular atenção para a França do séc. XVII, e a frequentar a Bibliothèque de France.

$\mathrm{O}$ interesse pelo estudo dos percursos formativos dos príncipes e dos Senhores, internamente àquele peculiar laboratório cultural que é a corte, na Europa, é ainda um dos traços distintivos do meu percurso de pesquisa (cf. FERRARI, 1996, 2000). A partir do livro Segni d'infanzia ("Sinais da infância"), que assinei com Roberta Balzarini, Monica Grandini, Sara Micotti Gazzotti, Marc Hamilton Smith, em 1991, até o livro de que sou a autora, Lo specchio, la pagina, le cose. Congegni pedagogici tra ieri e oggi ("O espelho, a página, as coisas. Mecanismos pedagógicos entre o passado e o presente”, 2011), o interesse por essas temáticas sempre me acompanhou. Ao longo dos anos estendeu-se a outras infâncias principescas do passado, aos filhos dos Senhores de Milão e de Mântua no séc. XV, por exemplo. (FERRARI, 2000).

A perspectiva de pesquisa sobre as vicissitudes formativas das elites do passado, que cultivei, visa essencialmente refletir sobre os mecanismos pedagógicos, do passado e do presente, entendidos como um conjunto de engrenagens que contêm em si um programa de ação, capaz de orientar os percursos de identificação das pessoas e dos grupos sociais. Interessam-me as complexas vicissitudes que, entre ser e dever ser, determinam o devir de alguns indivíduos "excelentes". E isso por vários motivos. Antes de mais nada, embora dispersas em vários arquivos públicos e privados, bibliotecas, museus, estradas e praças, não faltam as fontes, de diversos tipos, que dão seu testemunho. Além disso, porque a análise dos traços de um itinerário formativo (imaginado, projetado e às vezes realizado) para aqueles que, na sociedade europeia do passado, eram chamados, por nascimento, a "reger os outros", traz à luz os vínculos que ligam as questões pedagógicas às questões políticas para os poucos e para os muitos. A análise de tais percursos formativos e dos dispositivos, explícitos e/ou latentes, a eles subjacentes, implica em uma perspectiva de investigação para além dos recintos disciplinares, segundo o modelo de tantos percursos de pesquisa discutidos e realizados no âmbito das atividades da École des Hautes Études en Sciences Sociales que tive a oportunidade de frequentar, como aluna, na metade dos anos oitenta (entre 1985 e 1987). Eram os anos em que Louis Marin discutia sobre os mecanismos de representação do poder na sociedade de antigo regime (MARIN, 1981), enquanto Roger Chartier refletia sobre o conceito de práticas 
culturais. (CHARTIER, 1995). Como conclusão de minha frequência bienal aos cursos da EHESS (e, em particular, aos seminários de Dominique Julia, de Roger Chartier, de Louis Marin) obtive, em setembro de 1987, um D.E.A. (Diplôme d'Études Approfondies) em Histoire et civilizations. No Mémoire que apresentei para a conclusão do curso, intitulado L'image du souverain dans les Institutions du prince en France pendant la minorité de Louis XIV, discuti as imagens de soberano em percursos pedagógicos articulados em modelos e antimodelos, salientando sua importância na construção da identidade do futuro príncipe e dos modos em que o poder político se dá como espetáculo e se representa.

Tal itinerário de estudos - nunca interrompido - do qual parti, que concerne aos pontos em que na Europa moderna as questões pedagógicas e políticas se intersectam em torno de um sujeito de "exceção", em virtude do seu "destino" social, atravessava os contextos educativos do presente em 1987, quando fui admitida à frequência do III ciclo do doutorado em Pedagogia da Faculdade de Letras e Filosofia da Universidade "La Sapienza", de Roma.

Não hesito em dizer que aqui se situa, sem dúvida, outro dos pontos marcantes do meu itinerário cultural. A análise das políticas educativas e dos contextos do educar no presente, a partir da minha tese de doutorado, dedicada à avaliação da qualidade das creches italianas, defendida em 1991 (orientadores: Egle Becchi e Aldo Visalberghi), levou-me a princípio a realizar um reconhecimento da geografia das creches e das políticas para a infância na Itália entre 1987 e 1990 e, sucessivamente, a adaptar à situação italiana um instrumento americano de avaliação da qualidade da creche: a SVANI, de Harms, Cryer e Clifford (1992 [1990]).

Assim começa a delinear-se outro traço de meu peculiar percurso de pesquisa, que me levará mais tarde a refletir sobre o significado de operações de educational evaluation em contextos educativos (FERRARI, 1994; BONDIOLI; FERRARI, 2000, 2004b; BECCHI; BONDIOLI; FERRARI, 2005), a construir e/ou testar em campo, em diferentes itinerários de investigação, alguns instrumentos de avaliação da qualidade dos ambientes formativos em que crescem os cidadãos. (BECCHI; BONDIOLI; FERRARI, 1999; FERRARI, 1998; BONDIOLI et al., 2001; FERRARI, 2001; FERRARI; PITTURELLI, 2008, FERRARI; LEDDA, 2012). De fato, interessavam-me e ainda me interessam - ratifico-o - os mecanismos pedagógicos que - entre ideologias, estratégias e materialidade - influenciam as atitudes culturais, no cruzamento de paideia e politeia e, portanto, também aqueles dispositivos que são os instrumentos de avaliação da qualidade educativa dos contextos em que acontecem as relações de ensino-aprendizagem.

Como já disse, os meus interesses de estudos e de pesquisa foram se especificando ao longo dos anos, graças às pessoas que encontrei, graças a múltiplas 
experiências, graças aos cursos de que pude desfrutar nas diversas instituições que frequentei: o liceu clássico de Cremona, a Faculdade de Letras e Filosofia da Universidade de Pavia, o EHESS [École des Hautes Ètudes en Sciences Sociales ] de Paris, o doutorado em Pedagogia na Universidade "Sapienza", de Roma. Não posso deixar de mencionar o pós-doutorado em Ciências históricas na Universidade de Pavia (que frequentei quando já era professora efetiva na escola secundária, com afastamento por motivos de estudo) e o magistério na escola secundária de segundo grau (desde 1992, até que me tornei pesquisadora na Universidade de Pavia, em 2001). O trabalho na escola, antes em um instituto profissionalizante, depois em um liceu sociopsicopedagógico, ajudou-me a viver pessoalmente uma série de experiências, a "compreender" as questões relativas à vida quotidiana de professores e alunos em classe, a conhecer as inter-relações entre os diversos níveis sistêmicos que têm influência sobre a qualidade da oferta formativa e sobre os modos em que os seres humanos aprendem coisas novas...

Nesse percurso de identificação, humano e profissional, as influências e as sugestões foram muitas. Recordarei aqui somente uma atitude cultural que certamente extraí de tudo isso: a consciência da complexidade e da onipervasividade dos fenômenos pedagógicos. Tais fenômenos encontram-se sempre no cruzamento de diversas trilhas e das questões "políticas", que estão na raiz das ideias de cidadania (FERRARI, 2010b), permeiam o tecido de que somos feitos. (FERRARI; MORANDI; PLATÉ, 2011).

As minhas experiências de trabalho e de pesquisa se entrecruzaram ao longo dos anos: continuei a colaborar com os "grupos", bastante mutáveis na sua fisionomia, de pessoas que participavam de diferentes projetos com Egle Becchi e com Anna Bondioli, no programa pedagógico da Faculdade de Letras e Filosofia da Universidade de Pavia. Mesmo antes de ser enquadrada na carreira, na Universidade de Pavia, tive responsabilidade direta, como professora contratada, na condução de cursos universitários em Ferrara e Pavia, relativos a temáticas pedagógicas e histórico-pedagógicas; além dos numerosos projetos de pesquisa-ação pelos quais fui responsável, com outros ou sozinha, sobre o tema da avaliação da qualidade das instituições educativas de várias ordens e graus, julgo determinante no âmbito do meu itinerário pessoal de identificação profissional o fato de ter sido docente de diversos cursos ("Avaliação do contexto" e "Gestão da turma") para a formação dos professores secundários junto à Universidade pavese, desde o primeiro ano de instituição da SILSIS (Scuola Interuniversitaria Lombarda di Specializzazione all'Insegnamento Secondario) seção Pavia (1999/2000) até seu fechamento (em 2008). Não por acaso em 2003 dediquei um livro ao meu trabalho com os alunos de especialização (FERRARI, 2003); em tal análise teve um papel importante um debate sobre a reflexividade na prática profissional especializada que estava se desenvol- 
vendo naqueles anos (SCHÖN, 1983, 2006 [1987]), com particular ênfase aos profissionais da educação. Desde 2002 sou coordenadora da Área 1, relativa às ciências sociopsicopedagógicas para a formação docente da SILSIS pavese; nesse período pude, entre outras coisas, trabalhar na construção compartilhada de um instrumento para a avaliação da qualidade da oferta formativa dirigido aos alunos da especialização, depois organizado e publicado por mim, em 2011. (FERRARI, 2011b).

Em 2012 foi publicado um texto em que se explicita o meu interesse pela reflexão sobre as atitudes culturais, a partir do tema da intercultura, hoje não somente na Itália no centro de um amplo debate que ajuda a repensar o próprio conceito de cidadania. Como no caso do SASI-S (FERRARI; PITTURELLI, 2008), a oportunidade relativa à construção compartilhada desse instrumento está ligada ao fato de ter sido orientadora de um professor que estava frequentando um doutorado na Universidade pavese; com ele compartilhei a experiência de elaboração do Strumento per l'Autovalutazione dei Processi Interculturali in Educazione nella Scuola Secondaria di Secondo Grado. (FERRARI; LEDDA, 2012).

C.M. \& G.S.: Seu itinerário formativo revela um conjunto de interesses de pesquisa. Como você considera o tema da avaliação de contextos educativos e como vê a articulação com o aspecto reflexivo a que os profissionais e demais participantes envolvidos são chamados a realizar?

M.F.: No momento em que eu estava elaborando a minha tese de doutorado, entre 1987 e 1991, na Itália não tinha nascido aquele organismo denominado, em 1997, SNQI (Servizio Nazionale per la Qualità dell'Istruzione) ligado ao $\mathrm{CEDE}^{11}$, depois reordenado em 1999. Quando Egle Becchi me propôs traduzir e adaptar à situação italiana a ECERS [Early Chilhood Environment Rating Scale], publicada em 1980 por Harms e Clifford, e a ITERS [Infant/Todler Environment Rating Scale], ainda em vias de validação, depois publicada por Harms, Cryer e Clifford, em 1990, era necessário fazer referência ao debate internacional sobre o tema. Outros países antes da Itália haviam tomado a iniciativa para a construção de instrumentos pedagógicos úteis para refletir sobre a qualidade da oferta formativa dos contextos para a primeira infância (e não somente). As viagens para os Estados Unidos, a discussão com Thelma Harms, Debby Cryer, Richard Clifford e Egle Becchi, em função da tradução italiana da ITERS e da ECERS, ajudaram-me a compreender o quanto os dispositivos avaliativos são caracterizados por uma filosofia de base que orienta toda a prática avaliativa.

11 Centro Europeu da Educação, instituído com Decreto nº 419 do Presidente da República, em 31 de maio de 1974. 
As experiências de avaliação da qualidade educativa foram então progressivamente se consolidando junto com uma reflexão teórica sobre o próprio conceito de "dispositivo pedagógico", entre o passado e o presente. Para operar aquela que com Schön (1993 [1983]) poderíamos definir uma "epistemologia da prática", é necessário, porém, na minha opinião, trabalhar em várias direções. Os documentos da escola, entre passado e presente (FERRARI; MORANDI, 2007) e entre ser e dever ser, são preciosos testemunhos do desdobrar-se de mecanismos pedagógicos, frequentemente sobrepostos, que veiculam atitudes culturais e costumes educativos difundidos, às vezes, irrefletidos. Ao longo dos anos construí, portanto, o interesse por instrumentos de avaliação da qualidade educativa "transversais" a escolas de vários níveis e etapas, para promover oportunidades de análise pedagógica em que os educadores e os professores possam crescer, juntos, em consciência, acerca das próprias atitudes culturais, e desenvolver um léxico comum. (FERRARI, 1998, 2001; FERRARI; PITTURELLI, 2008). Mas isso não basta; creio que seja importante desenvolver metodologias capazes de analisar as complexas fontes da "cultura" da escola, a partir das declarações de intenções, em que se explicita o pacto entre um ambiente educativo e os usuários. (FERRARI, 2010b). Creio também que seja importante observar o quotidiano a partir dos objetos que docentes e alunos carregam de significado, refletir sobre os modos em que a escola "produz cultura" (como afirma CHERVEL, 1998) no seu próprio interior e na complexa ecologia sistêmica (BRONFENBRENNER, 1986 [1979]) em que está inserida. Graças à colaboração com vários órgãos (o Município de Mântua, o Arquivo de Estado de Cremona) pude ser responsável, na qualidade de diretora do Centro de pesquisa interdepartamental para o estudo e a valorização dos bens culturais escolares e educativos da Universidade de Pavia (desde 2006), por um longo percurso de pesquisa, dedicado à "lição das coisas" nos ambientes educativos, que originou vários eventos - mostras (FERRARI; MORANDI; PLATÉ, 2008), seminários e congressos - e publicações. (FERRARI; MORANDI; PLATÉ, 2011). Hoje um site documenta alguns aspectos do nosso trabalho comum ( $<$ http://www-5.unipv.it/lezcose $>)$. Estou convencida de que a profissionalidade dos educadores, dos professores e, mais em geral, de todos os profissionais, é um aspecto essencial e constitutivo da sociedade civil, um tema sobre o qual é necessário refletir, em itinerários de pesquisa que coloquem no centro as questões pedagógicas, os mecanismos, frequentemente latentes, que estão na base da expertise, para reconstruir as ideias de cidadão que se tem - mais ou menos conscientemente - em mente. Também por isso, juntamente com Egle Becchi e em colaboração com o Collegio Ghislieri de Pavia, além de vários Departamentos da Universidade pavese, contribuí para organizar uma série de seminários e publicar alguns livros, dedicados a uma "história pedagógica das profissões" (BECCHI; FERRARI, 2009; FERRARI; 
MAZZARELLO, 2010; FERRARI; LEDDA, 2011), a partir de uma acepção dilatada do conceito de "profissional", que se baseia no exercício declarado de uma competência especializada. Tal ideia de profissionalização compreende profissões não organizadas em "ordens", que têm um estatuto social diferente em relação a outras profissões mais fortes e reconhecidas, por tradição cultural, no Ocidente. Isso me permitiu refletir, a partir de estudos de caso, sobre os percursos de identificação sociais e profissionais de indivíduos e de grupos.

Ter organizado seminários e congressos (sobre os costumes educativos em determinados momentos e contextos da história do Ocidente - FERRARI, 2010a -, sobre a "lição das coisas" - FERRARI; MORANDI; PLATÉ, 2011), ser corresponsável por uma série de livros (e de seminários) sobre a "história pedagógica das profissões" - Becchi e Ferrari (2009) - significou para mim nestes últimos anos principalmente abrir um diálogo com colegas pertencentes a diferentes setores científico-disciplinares, reforçando a minha convicção de uma necessária abertura, in primis, dos horizontes culturais, em função do objeto que está no centro do itinerário de pesquisa e não do setor científico-disciplinar no qual se está institucionalmente inscrito.

\section{Donatella Savio}

\section{C.M. \& G.S.: Donatella, você poderia nos falar sobre suas "raízes" e sua formação universitária?}

D.S.: A solicitação de contar o meu percurso de crescimento como pesquisadora, a minha história desde quando era menina, parece-me estimulante e, no que me diz respeito, muito significativa. Entre os meus principais interesses de pesquisa está a brincadeira simbólica infantil; é um interesse que tem sólidas raízes na minha infância, especialmente nos longos verões transcorridos em uma pequena cidade do interior. A rede social, de apoio e monitoramento, que caracterizava aquela pequena comunidade tornava possível aos pais conceder autonomia e liberdade às crianças, em condições de segurança. Desde muito pequena, $4 / 5$ anos, portanto, tive a possibilidade de transcorrer dias inteiros fora de casa, junto com crianças de várias idades, todas mais velhas do que eu, sem nenhuma interferência adulta, com poucas exigências de horários e muita variedade de espaços e materiais para explorar; em suma, em condições que apresentavam muitos dos aspectos favoráveis para a brincadeira, segundo a literatura: ambiente rico de estímulos, vários e versáteis, plena autonomia de iniciativa, sólidas relações de amizade entre pares e "bons" exemplos lúdicos, 
fornecidos pelas crianças maiores. Tudo isso para mim significou a possibilidade de brincar muito, de modo rico e plenamente satisfatório, tanto que ainda hoje tenho uma recordação vívida das minhas brincadeiras infantis. Provavelmente é justamente a intensidade ainda forte das vivências ligadas às minhas experiências lúdicas que me levou, sem hesitações, a pôr a brincadeira no centro dos meus interesses de pesquisa desde logo: um modo para manter vivo o contato com uma experiência que eu sentia como altamente significativa para o meu crescimento pessoal; e, por isso, eu me sentia muito motivada a me aprofundar nas suas características e também no seu significado evolutivo e educativo.

Já como trabalho de conclusão do curso de graduação, na Universidade de Pavia, em 1986 (orientadora: Egle Becchi), enfrentei as questões da observação e da análise dos comportamentos lúdico-simbólicos infantis, realizando uma pesquisa exploratória no interior de um contexto pré-escolar. Interessava-me particularmente aprofundar a dimensão afetiva, ou seja, a conexão entre temas lúdicos e mundo interno infantil; por isso, escolhi as teorias psicanalíticas sobre a brincadeira como "instrumento" para a análise dos dados observados.

Desde o início da minha formação como pesquisadora, portanto, enfrentei algumas das questões que mais caracterizaram o trabalho de pesquisa dos Professores de Pedagogia da Universidade de Pavia. Em primeiro lugar, justamente, a brincadeira, investigada nas suas características sob uma ótica pedagógica, ou seja, enquanto realidade crucial para o crescimento infantil e, portanto, para a relação educativa, sobretudo em idade pré-escolar. Em segundo lugar, o entrelaçamento entre teoria e práxis, ou seja, o interrogar a realidade educativa concreta e refletir sobre ela utilizando hipóteses teóricas como dispositivos de pesquisa, com referência à teoria deweyana. No caso da minha pesquisa para a monografia de conclusão de curso de graduação, a realidade "interrogada" foi a brincadeira simbólica de grupos de crianças observadas na sua escola. Uma escola especial, ela mesma, laboratório de uma investigação educativa deweyanamente reflexiva. Tratava-se, de fato, de uma experimentação de continuidade educativa entre creche (0-3 anos) e pré-escola (3-6 anos), projetada e realizada nos anos oitenta por Egle Becchi e Anna Bondioli, como Professoras de Pedagogia da Universidade de Pavia, em colaboração com o Município de Garlasco (província de Pavia) e com os profissionais das instituições envolvidas; a experimentação pôs à prova como fio condutor da continuidade educativa a atividade simbólica e, portanto, justamente a brincadeira e a narração, com elaboração e testagem de propostas educativas pretendidas. (BONDIOLI, 1991). Portanto, um enlace entre teoria e práxis, mas também entre "teóricos" - os pesquisadores - e "práticos" - os professores e os educadores -, que colocava no centro das próprias pesquisas reflexivas a atividade lúdico-simbólica entendida como recurso educativo. Repensando tudo isso da minha atual perspectiva, posso dizer que o encontro 
com essa experiência experimental continha in nuce todos os elementos que eu iria desenvolver nos meus percursos de pesquisa.

Com o trabalho de doutorado, título que obtive em 1991, com a orientação de Egle Becchi e Clotilde Pontecorvo, prossegui a pesquisa sobre o jogo simbólico, na mesma escola de Garlasco, aprofundando a dimensão educativa. Dois os aspectos que me interessava investigar: de um lado a natureza do jogo simbólico e o seu papel evolutivo, ou seja, as competências que o atravessam e que contribuem para formar; de outro lado as modalidades com as quais um adulto educador pode relacionar-se com as condutas lúdico-simbólicas da criança sem desnaturá-las, mas, ao contrário, contribuindo para promovê-las. O ponto principal era desafiar e recompor uma presumível incompatibilidade entre brincadeira e educação, segundo a qual se há brincadeira, ou seja, livre e espontâneo relacionar-se das crianças com o mundo por puro prazer, não pode haver educação, ou seja, propostas e relações projetadas pelos adultos para conduzir quem é educado em direção a certas linhas de chegada evolutivas.

O método de investigação que adotei para enfrentar essas interrogações sempre foi o de um estreito diálogo entre dados empíricos e hipóteses teóricas, mas "praticado" desta vez de acordo com uma estrutura experimental. Para delinear modalidades de ação do adulto que, como hipótese, eu considerava capaz de promover a brincadeira simbólica infantil, baseei-me tanto em um filão de estudos sobre o training de brincadeira desenvolvido principalmente nos Estados Unidos nos anos setenta-oitenta, quanto nas reflexões psicanáliticas e na teoria vygostskiana, com a sua elaboração na teoria do tutoring (WOOD; BRUNER; ROSS, 1976), que traduzi em termos de relação educativa centrada na brincadeira. Em síntese extrema, cheguei a definir um estilo de relação entre adulto e brincadeira infantil caracterizada por: envolvimento direto na brincadeira, consideração e respeito pelas iniciativas lúdicas infantis, mas também reproposição com a introdução de estímulos temáticos coerentes e condutas correspondentes a níveis de competência lúdica pouco superiores àqueles ativados pelas crianças, para agir sobre a "zona de desenvolvimento proximal”. Verifiquei a eficácia desse estilo de intervenção, colocando-o em ato com um grupo de crianças por cerca de um mês, nos momentos livres de seu dia na escola, observando e avaliando as suas competências lúdicas antes e depois disso e comparando-as com as dos outros dois grupos de crianças não submetidas ao mesmo tratamento experimental. (BONDIOLI; SAVIO, 1994a; SAVIO, 1995a). A verificação positiva desse estilo interativo foi o primeiro passo de sucessivos aprofundamentos realizados junto com Anna Bondioli, que levaram a colocá-lo teoricamente nos termos de uma relação educativa caracterizada como "promoção a partir do interno". (BONDIOLI, 1997).

A prova da intervenção exigia observar/avaliar as competências do jogo simbólico de maneira pontual e replicável; essa exigência, por outro lado, 
casava-se com a minha intenção de especificar a natureza do jogo simbólico e o seu papel evolutivo. Por isso uma articulação importante da minha pesquisa de doutorado consistiu também na elaboração de um instrumento para a avaliação das habilidades lúdico-simbólicas infantis, o SVALSI. A organização desse instrumento foi proficuamente marcada pelo encontro com Greta Fein (Universidade de Maryland, Estados Unidos), estudiosa da brincadeira que sugeriu importantes especificações; o SVALSI foi ulteriormente detalhado e então validado com uma pesquisa realizada sucessivamente ao trabalho de doutorado, juntamente com Anna Bondioli. (BONDIOLI; SAVIO, 1994a).

Se com a SVALSI eu considerava ter feito uma recapitulação sobre as dimensões sociocognitivas que caracterizam a brincadeira e sobre como levantá-las, não tinha abandonado o interesse pela relação entre atividade lúdica e afetividade, cultivado com a monografia de graduação, interesse que me levou a buscar uma metodologia de observação ad hoc: de fato, era totalmente evidente que as vivências emotivas expressas pela criança na brincadeira não podiam ser captados através da "simples", embora analítica, descrição e codificação dos comportamentos lúdicos observados. Para responder a esse interesse foi fundamental a minha participação (1987-92) no curso de "Formação psicodinâmica para educadores das instituições para a infância", na Clínica de Neuropsiquiatria Infantil da Universidade de Torino que, em estreita colaboração com a Tavistok Clinic de Londres, propunha um percurso formativo centrado na infant observation. Essa metodologia de observação para fins formativos, organizada por Ester Bick com base na teoria de M. Klein, e chegada na Itália em torno da metade dos anos setenta, propõe substancialmente que se considerem os comportamentos lúdicos infantis como manifestações simbólicas de significados afetivos profundos, que podem ser captados pelo observador através de uma análise "teoricamente informada" das próprias vivências emotivas. Uma metodologia, portanto, com a qual quem observa olha conscientemente para dentro de si para encontrar o sentido daquilo que vê diante de si: um instrumento importante para ir a fundo na natureza evolutiva do jogo simbólico, mas sem dúvida útil também em relação à metodologia de pesquisa centrada no enlace reflexivo entre teoria e práxis, por mim tomada como ponto de referência. $\mathrm{O}$ curso previa também uma experiência de work discussion, com a qual tive a oportunidade de supervisionar os encontros do grupo de educadores de Garlasco para o monitoramento da experimentação e de adquirir assim competências sobre as dinâmicas profundas dos grupos de trabalho que me seriam úteis no meu futuro papel de formadora, como direi mais adiante.

A atenção pelas dimensões emotivas da brincadeira não significou a extinção do meu interesse pela sua dimensão sociocognitiva. Com o aperfeiçoamento devido ao pós-doutorado (1991-1994), que obtive em Trieste sob a supervisão 
de Lucia Lumbelli, enfrentei o tema da "teoria da mente", que naqueles anos entre o fim dos anos oitenta e nos anos noventa - era um dos focos de interesse da psicologia cognitiva, e em particular das investigações de pesquisadores da Cognitive Developmental Unit de Londres, como S. Baron-Choen, U. Frith, A. Leslie. O que me interessava aprofundar era a relação, já tematizada por A. Leslie, entre o jogo simbólico e a "teoria da mente", ou seja, a capacidade de reconhecer uma realidade mental junto àquela física e, portanto, de atribuir a si mesmo e aos outros estados mentais como crenças, intenções, esperanças, "fazer de conta que", etc. Repropondo uma experiência de A. Leslie, clássico nesse âmbito de pesquisa, pus o acento sobre a dimensão relacional da estrutura experimental: a criança, espectador de uma cena com bonequinhas movidas pelo pesquisador, reconhece mais facilmente a "falsa crença" induzida em um dos personagens e, portanto, demonstra possuir uma "teoria da mente", quando o pesquisador se dirige a ela utilizando o espelhamento não diretivo rogersiano. (SAVIO, 1995b). Portanto, mesmo nos limites de uma metodologia estritamente experimental, eu havia focalizado um aspecto educativo em conexão com o jogo simbólico: um adulto que intervém de modo não diretivo pode promover na criança a expressão de capacidades que estariam na base, segundo a psicologia cognitiva, da competência lúdico-simbólica e que não se manifestaria sem aquela intervenção; isso poderia querer dizer, em uma perspectiva vygotskiana, que a intervenção ativa a "zona de desenvolvimento proximal" e, portanto, tem um efeito educativo.

\section{C.M. \& G.S.: Seria a partir de tais considerações quanto à interven- ção do adulto, em uma modalidade específica, não diretiva, que surge seu interesse e experiência como "formadora de formadores"?}

D.S.: Já durante o pós-doutorado a minha formação como pesquisadora se entreteceu com a minha atividade de formadora de educadores e professores, realizada principalmente em âmbito pré-escolar, e contínua por mais de vinte anos, até hoje. A minha abordagem como formadora foi e é caracterizada pela proposta e supervisão de percursos de investigação: qualquer que seja o tema sobre o qual os educadores e professores me pedem uma intervenção formativa, a minha resposta é sempre, na medida do possível, a elaboração e a realização, juntamente com eles, de um percurso de investigação reflexivo, com definição do problema/pergunta que se quer responder e das possíveis respostas, coleta de dados, análise dos dados e discussão para verificar a plausibilidade das respostas previstas como hipóteses. Essa modalidade de interpretação do meu papel de formadora me deu condição de desenvolver e ampliar os meus interesses de pesquisa, oferecendo-me a possibilidade de coletar e analisar dados empíricos (observações, questionários, etc.), mas também e, principalmente, as ricas reflexões desenvolvidas com educadores e professores. 
Fundamental para o afinamento do meu olhar de pesquisadora sobre tal material, além da minha formação psicodinâmica sobre as características dos grupos de trabalho, de que já falei, foi a frequência à Escola quadrienal de Formação em Psicoterapia Familiar Sistêmica, no Centro milanês de Terapia da família, dirigido por L. Boscolo e G. Cecchin (1995-98). O encontro com a abordagem sistêmica ao mesmo tempo alargou e "liberou" a minha perspectiva, sugerindo-me conexões antes invisíveis no meu investigar reflexivo, mas principalmente convidando-me a fazer proliferar as hipóteses de sentido, pondo como único filtro a sua "utilidade" ao fornecer uma explicação plausível da realidade investigada. Com esse "novo olhar" me voltei novamente ao jogo simbólico, unindo o interesse pelo estilo de intervenção do adulto com o interesse pela metodologia da observação. Já com a pesquisa para o pós-doutorado, desenvolvido na Universidade de Trieste, eu havia proposto que o levantamento das competências infantis, se acontece dentro da relação entre adulto observador e criança observada, pode dizer mais, fornecer indicações mais úteis para esclarecer a natureza e o grau daquelas competências. Desenvolvi essa perspectiva analisando os protocolos de observação de uma relação lúdica entre um adulto e um grupo infantil na creche, interpretando-a como uma investigação em que o adulto, na posição de observador partícipe, que "promove de dentro", enfrenta os seguintes passos: formula hipóteses sobre o sentido do comportamento infantil e sobre o grau de competência lúdica que exprime; põe à prova essas hipóteses, propondo-as à criança, ou seja, ativando aquele nível de competência através do próprio comportamento lúdico; espera o feedback, verificando a hipótese através da compreensão ou incompreensão que a criança manifesta, e assim delineia as fronteiras de sua zona de desenvolvimento proximal. (SAVIO, 2007). O meu papel de formadora em estreito contato com os serviços educativos pré-escolares me levou a desenvolver o interesse pela observação dos comportamentos infantis além das condutas lúdico-simbólicas; efetivamente, aprofundei o tema da avaliação da criança tanto em termos epistemológicos (SAVIO, 2000a) quanto em relação ao processo de programação educativa. (SAVIO, 2006). Isso significou, por um lado, em uma ótica sistêmica, propor a observação/avaliação da criança como o resultado de um processo de construção compartilhada no qual interveem as premissas culturais dos avaliadores (as ideias de criança, de desenvolvimento, de avaliação dos professores) e no qual se refletem a qualidade das relações entre níveis sistêmicos (entre os professores, entre professores e família, etc.); por outro lado, organizar indicações operativas que permitam construir compartilhando uma versão da criança conscientemente provisória, a mais útil possível para projetar percursos educativos ad hoc.

Um passo além, em que encontraram síntese a ideia da observação como processo de investigação e a de relação educativa como "promoção a partir do 
interno", consistiu em propor a própria relação educativa como um percurso de investigação, caracterizado pela transação e reflexividade de matriz deweyana, em sintonia com uma das perspectivas tematizadas pelas Professoras de Pedagogia de Pavia: a ação educativa é elaborada como hipótese de ações que podem obter efeitos evolutivos, a partir daquilo que a criança propõe e com base nas premissas, convicções, saberes, da professora; é, portanto, colocada à prova dentro da relação com a criança e verificada em termos de correspondência entre efeitos esperados e efeitos obtidos. (SAVIO, 2000b).

A minha atuação como formadora estimulou também o interesse por um novo tema, tocado somente transversalmente pelos meus percursos de pesquisa, o das características contextuais favoráveis à promoção da brincadeira e do desenvolvimento infantil, ou seja, no final das contas, das características de um contexto educativo de qualidade. A minha relação com as Professoras de Pedagogia de Pavia, mantida sempre viva, contribuiu para desenvolver o meu interesse pela qualidade do contexto educativo na perspectiva da educational evaluation e de seu uso como instrumento para a formação de educadores e professores em um grupo de trabalho. Participei de diversas pesquisas realizadas pelo "grupo" de pesquisa da Universidade de Pavia, para a organização de instrumentos idôneos para o levantamento de dados e avaliação das características de contextos educativos extrafamiliares. Em especial, colaborei com a construção de um instrumento de autoavaliação da pré-escola - AVSI (BONDIOLI et al., 2008); de uma bateria de questionários para o levantamento das características organizacionais e gerenciais das creches e das pré-escolas (SAVIO, 2004); de um instrumento de autoavaliação da qualidade lúdica da creche. (SAVIO, 2011).

\section{C.M. \& G.S.: Atualmente, nas suas pesquisas junto ao grupo pavese, a qual temática vem se dedicando?}

D.S.: Tornei-me pesquisadora por tempo indeterminado na Universidade de Pavia em 2008. Isso me permitiu aprofundar a pesquisa sobre o papel formativo da autoavaliação de contexto segundo uma perspectiva que sempre compartilhei com as minhas colegas de hoje e com Egle Becchi: os processos de crescimento profissional, do indivíduo e do grupo de educadores, são favorecidos pelos instrumentos para a avaliação de contexto, principalmente quando são os operadores a utilizá-los para autoavaliar o próprio serviço ou a própria escola e a confrontar-se depois com as recíprocas avaliações, com a ajuda de um formador. Isso me levou a refletir sobre o tema da "identidade educativa de contexto", entendida como conjunto dos valores/saberes e das relativas práticas educativas comuns a um certo grupo de trabalho de uma certa instituição (uma creche, uma escola ou todas as creches/todas as escolas de um certo território), no qual os educadores/professores individualmente se baseiam, de modo mais ou menos 
explícito, consequentemente orientando sua própria atuação. Com essa base, a formação de um grupo de educadores/professores pode se configurar como promoção de um debate que conduz à negociação e definição de uma identidade educativa comum e explícita, com o consequente reforço da intencionalidade e consciência profissional de cada educador e do grupo.

Entre as metodologias úteis à realização dessa abordagem formativa, além da avaliação de contexto, como Professoras de Pedagogia da Universidade de Pavia, estamos investigando também um estilo de formador inspirado na "promoção a partir do interno", já definido na relação educativa entre adulto e criança, principalmente na brincadeira, e orientado pelos seguintes princípios: troca paritária baseada na reciprocidade; promoção de processos de reflexão e de elaboração compartilhados; aprendizagem entendida como construção compartilhada de significados comuns. (BONDIOLI; SAVIO, 2009). Aprofundamos e estamos ainda aprofundando esse "estilo" em alguns percursos de pesquisa-formação que envolvem o conjunto das instituições 0-3 de alguns territórios e que visam justamente a definir, sobre vários aspectos do contexto, a "identidade educativa" da instituição daquele certo território. (BONDIOLI; NIGITO; SAVIO, 2008; SAVIO, 2008; BONDIOLI; SAVIO, 2012). Entre esses percursos, particularmente significativo do meu ponto de vista de pesquisadora, foi aquele realizado com as creches do Município de Módena (2005/2009), enquanto nele encontraram uma feliz conexão e desenvolvimento sinérgico os meus principais focos de interesse: a brincadeira, a avaliação de contexto, a formação reflexiva participativa. O percurso foi desenvolvido em torno do tema da brincadeira e do seu papel na relação educativa. A reflexão em grupo sobre esse tema, com o apoio de um formador que "promovia do interior", levou a dois resultados significativos sobre dois temas para mim cruciais. Em primeiro lugar sobre a brincadeira, que através da troca reflexiva tive a oportunidade de definir e argumentar teoricamente como "voz da criança", ouvindo como é possível colher as suas necessidades evolutivas para considerá-las na programação educativa e, portanto, torná-la partícipe, construtor-partícipe ativo dos próprios percursos de crescimento. (SAVIO, 2010). Em segundo lugar, sobre o modelo de formação participativa reflexiva, do qual pude pôr à prova as etapas e os instrumentos: a reflexão em grupo apoiada por um formador que "promove do interior", ao longo de todo o percurso; a construção de um instrumento para avaliar tal qualidade lúdica de uma creche, com base na definição de uma identidade educativa e lúdica comum; a aplicação do instrumento por parte dos próprios educadores, que assim se autoavaliaram; a reflexão sobre os resultados da autoavaliação com a identificação de pontos fortes e pontos fracos; a organização e a realização de um projeto de melhoria baseado nos resultados da autoavaliação. 


\section{REFERÊNCIAS}

ALTHUSSER, L. Idéologie et appareils idéologiques d'état (Notes pour une recherche). La Pensée, v. 151, p. 3-38,1970.

ANTONELLI, Q.; BECCHI, E. (a cura di.). Scritture bambine. Roma-Bari: Laterza, 1995. ARIÈS, P. Padri e figli nell'Europa medievale e moderna. (1960). Trad. it. Bari: Laterza, 1968.

BALZARINI, R.; FERRARI ALFANO, M.; GRANDINI, M.; MICOTTI GAZZOTTI, S.; HAMILTON SMITH, M. Segni d'infanzia. Crescere come re nel Seicento. Milano: FrancoAngeli, 1991.

BARBAGLI, M.; DEI, M. Le vestali della classe media. Bologna: Il Mulino, 1969.

BECCHI, E. Premessa. In: Quaderni. Fondazione GianGiacomo Feltrinelli, 23, Per una storia del costume educativo (Età classica e Medioevo), 1983. p. 1-5.

BECCHI , E. (a cura di.). Storia dell'educazione. Scandicci (FI): La Nuova Italia, 1987.

BECCHI, E. I bambini nella storia. Roma-Bari: Laterza, 1994.

BECCHI, E. (a cura di.). Manuale della scuola del bambino dai tre ai sei anni. Milano: FrancoAngeli, 1995.

BECCHI, E. Pedagogie latenti: una nota. Quaderni di didattica della scrittura, v. 3, p. 105-113, 2005.

BECCHI, E. Maschietti e bambine. Pisa: ETS, 2011.

BECCHI, E.; BONDIOLI, A. L'asilo nido nel pavese: risultati di una ricerca. Pavia: Amministrazione Provinciale di Pavia, 1983.

BECCHI, E.; BONDIOLI, A. La scuola dell'infanzia nel pavese: risultati di una ricerca. Pavia: Amministrazione Provinciale di Pavia, 1984.

BECCHI, E.; BONDIOLI, A. (a cura di.). Valutare e valutarsi. Bergamo: Edizioni Junior, 1997. [BECCHI, E.; BONDIOLI, A. (Org.). Avaliando a pré-escola: uma trajetória de formação de professores. Tradução de: ORTALE, F. L.; MOREIRA, I. P. Campinas: Autores Associados, 2003].

BECCHI, E.; BONDIOLI, A.; FERRARI, M. ISQUEN: indicatori e scala di valutazione della qualità educativa del nido. In: CIPOLLONE, L. (a cura di.). Strumenti e indicatori per valutare il nido. Azzano San Paolo (BG): Edizioni Junior, 1999. p. 134-180. [BECCHI, E.; BONDIOLI, A.; FERRARI, M. ISQUEN: indicadores e escalas de avaliação da qualidade educativa da creche. In: CIPOLLONE, L. (Org.). Instrumentos e indicadores para avaliar a creche: um percurso de análise da qualidade. Tradução de: FRITOLI, L. E. Curitiba: Ed. UFPR, 2014. p. 149-186]. 
BECCHI, E.; BONDIOLI, A.; FERRARI, M. La stesura di un progetto pedagogico del nido valutabile. Indicazioni per la redazione. In: BONDIOLI, A. (a cura di.). Il progetto pedagogico del nido e la sua valutazione. Azzano San Paolo (BG): Edizioni Junior, 2002. p. 133-163. [BECCHI, E.; BONDIOLI, A. FERRARI, M. Escrever um projeto pedagógico da creche avaliável: indicações para a sua redação. In: BONDIOLI, A(Org.). O projeto pedagógico da creche e a sua avaliação: a qualidade negociada. Tradução de: ORTALE, F. L.; MOREIRA, I. P. Campinas: Autores Associados, 2004. p. 173-211].

BECCHI, E.; BONDIOLI, A.; FERRARI, M. (a cura di.). Scuole allo specchio. Ricerca-formazione con un gruppo di istituti comprensivi Lombardi. Milano: FrancoAngeli, 2005.

BECCHI, E.; BONDIOLI, A.; FERRARI, M.; GARIBOLDI A. Idee guida del nido d'infanzia. Azzano San Paolo (BG): Edizioni Junior, 2002. [BECCHI, E.; BONDIOLI, A.; FERRARI, M.; GARIBOLDI, A. Ideias orientadoras para a creche: a qualidade negociada. Tradução de: MENON, M. de L. T. Campinas: Autores Associados, 2012].

BECCHI, E.; FERRARI, M. Formare alle professioni. Sacerdoti, principi, educatori. Milano: FrancoAngeli, 2009.

BECCHI, E.; JULIA, D. (a cura di.). Storia dell'infanzia. Roma-Bari: Laterza, 1996. 2 v.

BECCHI, E.; SEMERARO, A. (a cura di.). Archivi d'infanzia. Per una storiografia della prima età. Milano: RCS libri-La Nuova Italia, 2001.

BONDIOLI, A. (a cura di.). Il buffone e il re. Il gioco del bambino e il sapere dell'adulto. Firenze: La Nuova Italia, 1989.

BONDIOLI, A. (a cura di.). Il bambino, il gioco, gli affetti. Per una pedagogia del simbolismo lúdico. Bergamo: Juvenilia, 1990.

BONDIOLI, A. Un servizio unificato per l'infanzia: l'esperienza di continuità dell'asilo nido e della scuola materna di Garlasco. In: CATARSI, E. (a cura di.). La continuità educativa tra asilo nido e scuola materna. Scandicci (FI): La Nuova Italia, 1991.

BONDIOLI, A. Uno strumento per l'analisi della giornata alla scuola materna. In: INSEGNAMENTI pedagogici del Dipartimento di Filosofia dell'Università di Pavia (a cura di.). La giornata educativa nella scuola dell'infanzia. Bergamo: Edizioni Junior, 1993. p. 1-16.

BONDIOLI, A. Gioco e educazione. Milano: FrancoAngeli, 1996.

BONDIOLI, A. Il processo di apprendimento al Nido: le offerte formative e il ruolo dell'adulto. In: TERZI, N.; BERZIGA, G.; BATTAGLIONI, B. (a cura di.). Il Nido compie 20 anni. Bergamo: Edizioni Junior, 1997. p. 67-82.

BONDIOLI, A. Riflettere sulla giornata scolastica: uno strumento e un percorso di valutazione formativa. In: BONDIOLI, A.; FERRARI, M. (a cura di.). Manuale di valutazione del contesto educativo: teorie, modelli, studi per la rilevazione della qualità della scuola. Milano: FrancoAngeli, 2000. p. 345-369. 
BONDIOLI, A. The Adult as a Tutor in Fostering Children's Symbolic Play. In: GONCU, A.; KLEIN, E. L. (Ed.). Children in Play, Story, and School. New York: Guilford Publications, 2001.p. 107-131.

BONDIOLI, A. (a cura di.). Il tempo nella quotidianità infantile. Azzano San Paolo (BG): Edizioni Junior, 2002a. [BONDIOLI, A. (Org.). O tempo no cotidiano infantil: perspectivas de pesquisa e estudo de casos. Tradução de: ORTALE, F. L.; MOREIRA, I. P. São Paulo: Cortez, 2004].

BONDIOLI, A. Dagli Indicatori alle condizioni del Progetto educativo: un percorso pedagogico-politico di definizione e assicurazione della qualità degli asili nido della Regione Emilia-Romagna. In: BONDIOLI, A. (a cura di.). Il progetto pedagogico del nido e la sua valutazione. Azzano San Paolo (BG): Edizioni Junior, 2002b. p. 11-25. [BONDIOLI, A. Dos indicadores às condições do projeto educativo: um percurso pedagógico-político de definição e garantia da qualidade das creches da região da Emília-Romanha. In: BONDIOLI, A. (Org.). O projeto pedagógico da creche e a sua avaliação. Tradução de: ORTALE, F. L.; MOREIRA, I. P. Campinas: Autores Associados, 2004. p. 13-33].

BONDIOLI, A. (a cura di.). Ludus in fabula. Per una pedagogia del narrare infantile. Azzano San Paolo (BG): Edizioni Junior, 2004a.

BONDIOLI, A. Spunti di riflessione su un servizio comunale a partire dallo studio della quotidianità. In: BONDIOLI, A.; FERRARI, M. (a cura di.). Verso un modello di valutazione formativa. Ragioni, strumenti e percorsi. Azzano San Paolo (BG): Edizioni Junior, 2004b. p. 325-360.

BONDIOLI, A. Promuovere dall'interno. In: BONDIOLI, A.; FERRARI, M. (a cura di.). Educare la professionalità degli operatori per l'infanzia. Azzano San Paolo (BG): Edizioni Junior, 2004c. p. 61-76.

BONDIOLI, A. (a cura di.). L'osservazione in campo educativo. Azzano San Paolo (BG): Edizioni Junior, 2007.

BONDIOLI, A. DAVOPSI, Dispositivo di Analisi e Valutazione dell'Organizzazione Pedagogica della Scuola dell'Infanzia. In: BONDIOLI, A.; NIGITO, G. (a cura di.). Tempi, spazi, raggruppamenti. Azzano San Paolo (BG): Edizioni Junior, 2008. p. 115-257.

BONDIOLI, A. Una pedagogia per l'infanzia. Relazione presentata al convegno su Ferrante Aporti, organizzata a Cremona, 2009.

BONDIOLI, A.; BECCHI, E.; FERRARI, M.; GARIBOLDI, A.; SAVIO, D. AVSI. AutoValutazione della Scuola dell'Infanzia. Roma-Milano: CEDE-FrancoAngeli, 2001.

BONDIOLI, A.; BECCHI, E.; FERRARI, M.; GARIBOLDI, A.; SAVIO, D. Lo strumento. In: BONDIOLI, A.; FERRARI, M. (a cura di.). AVSI. AutoValutazione della Scuola dell'Infanzia.Uno strumento di formazione e il suo collaudo. Azzano San Paolo (BG): Edizioni Junior, 2008. 
MORO, C.; SOUZA, G. de. Para uma análise pedagógica dos contextos educativos...

BONDIOLI, A.; DOMIMAGNI, M.; NIGITO, G.; SABBATINI, A. Elementi per Rilevare e Valutare l'Integrazione Scolastica (ERVIS). Azzano San Paolo (BG): Edizioni Junior, 2009.

BONDIOLI, A.; FERRARI, M. L'analisi della giornata educativa. Dirigenti scuola, v. XVIII, n. 3, p. 27-32, 1998.

BONDIOLI, A.; FERRARI, M. (a cura di.). Manuale di valutazione del contesto educativo: teorie, modelli, studi per la rilevazione della qualità della scuola. Milano: FrancoAngeli, 2000.

BONDIOLI, A.; FERRARI, M. (a cura di.). Educare la professionalità degli operatori per l'infanzia. Azzano San Paolo (BG): Edizioni Junior, 2004a.

BONDIOLI, A.; FERRARI, M. (a cura di.). Verso un modello di valutazione formativa. Ragioni, strumenti e percorsi. Azzano San Paolo (BG): Edizioni Junior, 2004b.

BONDIOLI, A.; FERRARI, M. (a cura di.). AVSI. AutoValutazione della Scuola dell'Infanzia. Uno strumento di valutazione e il suo collaudo. Azzano San Paolo (BG): Edizioni Junior, 2008a.

BONDIOLI, A.; FERRARI, M. (a cura di.). Manuale di valutazione del contesto educativo: teorie, modelli, studi per la rilevazione della qualità della scuola. Milano: FrancoAngeli, 2008b.

BONDIOLI, A.; FERRARI, M.; GARIBOLDI, A.; LIVRAGHI, P. La pedagogia dell'aula e i suoi modelli. In: BONDIOLI, A.; FERRARI, M. (a cura di.). Manuale di valutazione del contesto educativo: teorie, modelli, studi per la rilevazione della qualità della scuola. Milano: FrancoAngeli, 2000. p. 370-393.

BONDIOLI, A.; GHEDINI, P. O. (a cura di.). La qualità negoziata. Gli indicatori per i nidi della Regione Emilia Romagna. Azzano San Paolo (BG): Edizioni Junior, 2000.

BONDIOLI, A.; MANTOVANI, S. (a cura di.). Manuale critico dell'asilo nido. Milano: FrancoAngeli, 1987. [BONDIOLI, A.; MANTOVANI, S. (Org.). Manual de educação infantil: de 0 a 3 anos - uma abordagem reflexiva. Tradução de: DI LEONE, R. S.; OLMI, A. Porto Alegre: ArtMed, 1998].

BONDIOLI, A.; NIGITO, G. (a cura di.). Tempi, spazi, raggruppamenti. Azzano San Paolo (BG): Edizioni Junior, 2008.

BONDIOLI, A.; NIGITO, G.; SAVIO, D. L'elaborazione delle linee guida per i nidi di Siena: un percorso riflessivo. In: Le linee guida pedagogiche dei nidi di Siena. Ufficio stampa del Comune di Siena, 2008. p. 13-17.

BONDIOLI, A.; SAVIO, D. Osservare il gioco di finzione. Una scala di valutazione delle abilità ludico-simboliche infantili (SVALSI). Azzano San Paolo (BG): Edizioni Junior, 1994a.

BONDIOLI, A.; SAVIO, D. Play training as an action in children's zone of proximal development. Scientia paedagogica experimentalis, v. XXXI, n. 1, p. 45-68, 1994b. 
BONDIOLI, A.; SAVIO, D. Promoting from the inside: a model of fostering children's symbolic activities and its application. In: 17th EECERA Annual Conference, Praga, 29 Aug./1 Sep. 2007, p. 245.

BONDIOLI, A.; SAVIO, D. Empowering early childhood educators' professional development by a "maieutic approach". In: 18th EECERA Annual Conference, Stavanger, "Reconsidering the Basics in Early Childhood Education", 3-6 Sep. 2008. p. 153.

BONDIOLI, A.; SAVIO, D. Formare i formatori: un approccio maieutico. In: DOMENICI, G.; SEMERARO, M. L. (a cura di.). Le nuove sfide della ricerca didattica tra saperi, comunità sociali e culture. Roma: Monolite editrice, 2009. p. 373-391.

BONDIOLI, A.; SAVIO, D. (a cura di.). Partecipazione e qualità. Bergamo: Edizioni Junior, 2010. [BONDIOLI, A.; SAVIO, D. (Orgs). Participação e Qualidade em Educação da Infância: percursos de compartilhamento reflexivo em contextos educativos. Tradução de: FRITOLI, L. E. Curitiba: Ed. UFPR, 2013].

BONDIOLI, A.; SAVIO, D. (a cura di.). Educare nelle sezioni Primavera. Un'esperienza di formazione. Bergamo: Edizioni Junior, 2012.

BOURDIEU, P.; PASSERON, J.-C. La Reproduction. Éléments pour une théorie du système d'enseignement. Paris: Les Éditions de Minuit: 1970.

BRONFENBRENNER, U. Ecologia dello sviluppo umano. (1979). Trad. it. Bologna: Il Mulino, 1986.

BRUNER, J. La cultura dell'educazione. Nuovi orizzonti per la scuola. (1996). Trad. it. Milano: Feltrinelli, 1997.

CHARTIER, R. (Org.). Pratiques de la lecture. Marseille: Rivages, 1995.

CHERVEL, A. La culture scolaire. Une approche historique. Paris: Belin, 1998.

CORSARO, W. A. Le culture dei bambini. (1997). Trad. it. Bologna: il Mulino, 2003.

DARDER, P.; LÓPEZ, J. A. QUAFES. Questionario per l'Analisi del Funzionamento Educativo della Scuola. (1989). Adaptação italiana de: FERRARI, M. Milano: FrancoAngeli, 1998.

DARDER, P.; MESTRES, J. (a cura di.). ASEI. Autovalutazione dei servizi educativi per l'infanzia. (1994). Adaptação italiana de: GUSMINI, M. P. Milano: FrancoAngeli, 2000.

FEIN, G. G. Pretend Play in Childhood: An Integrative Review. Child Development, v. 52, p. 1095-1118, 1981.

FERRARI, M. (a cura di.). La valutazione di contesti prescolari: strumenti e realtà. Bergamo: Edizioni Junior, 1994.

FERRARI, M. La paideia del sovrano. Ideologie, strategie e materialità nell'educazione principesca del Seicento. Firenze: La Nuova Italia, 1996. 
FERRARI, M. Discutere il QUAFES: una ricerca nella scuola. In: DARDER, P.; LÓPEZ, J. A. QUAFES. Questionario per l'Analisi del Funzionamento Educativo della Scuola. Adaptação italiana de: FERRARI, M. Milano: FrancoAngeli, 1998. p. 82-112.

FERRARI, M. Per non manchare in tuto del debito mio. L'educazione dei bambini Sforza nel Quattrocento. Milano: FrancoAngeli, 2000.

FERRARI, M. (a cura di.). GAQUIS. Griglia di Analisi della Qualità Intrinseca della Scuola. Milano: FrancoAngeli, 2001.

FERRARI, M. La giornata educativa nella scuola elementare. In: BONDIOLI, A. (a cura di.). Il tempo nella quotidianità infantile. Azzano San Paolo (BG): Edizioni Junior, 2002. p. 91-104. [FERRARI, M. O dia-a-dia educativo na escola elementar. In: BONDIOLI, A. (Org.). O tempo no cotidiano infantil: perspectivas de pesquisa e estudos de caso. Tradução de: ORTALE, F. L.; MOREIRA, I. P. São Paulo: Cortez, 2004. p.105-119].

FERRARI, M. (a cura di.). Insegnare riflettendo. Proposte pedagogiche per i docenti della secondaria. Milano: FrancoAngeli, 2003.

FERRARI, M. (a cura di.). I bambini di una volta. Problemi di metodo. Studi per Egle Becchi. Milano: FrancoAngeli, 2006.

FERRARI, M. (a cura di.). Costumi educativi nelle corti europee (XIV-XVIII secolo). Pavia: Pavia University Press, 2010a.

FERRARI, M. (a cura di.). Carta dei servizi educativi e percorsi identitari. Il caso italiano e l'impegno dei Comuni. Azzano San Paolo (BG): Edizioni Junior, 2010b.

FERRARI, M. Lo specchio, la pagina, le cose. Congegni pedagogici tra ieri e oggi. Milano: FrancoAngeli, 2011a.

FERRARI, M. (a cura di.). VAL-SILSIS (PV). Strumenti di VALutazione elaborati dalla SILSIS - sezione di Pavia. Pavia: Pavia University Press, $2011 \mathrm{~b}$.

FERRARI, M.; LEDDA, F. (a cura di.). Formare alle professioni. La cultura militare tra passato e presente. Milano: FrancoAngeli, 2011.

FERRARI, M.; LEDDA, F. SAPIENSSII. Strumento per l'Autovalutazione dei Processi Interculturali in Educazione nella Scuola Secondaria di Secondo Grado. Milano: FrancoAngeli, 2012.

FERRARI, M.; MAZZARELLO, P. (a cura di.). Formare alle professioni. Figure della sanità. Milano: FrancoAngeli, 2010.

FERRARI, M.; MORANDI, M. (a cura di.). Documenti della scuola tra passato e presente. Problemi ed esperienze di ricerca per un'analisi tipologica delle fonti. Azzano San Paolo (BG): Edizioni Junior, 2007.

FERRARI, M.; MORANDI, M.; PLATÉ, E. La lezione delle cose. Oggetti didattici delle scuole dell'infanzia mantovane tra Ottocento e Novecento. Mantova: Comune di Mantova-Publi Paolini, 2008. 
FERRARI, M.; MORANDI, M.; PLATÉ, E. Lezioni di cose, lezioni di immagini. Studi di caso e percorsi di riflessione sulla scuola italiana tra XIX e XXI secolo. Parma: Spaggiari-Edizioni Junior, 2011.

FERRARI, M.; PITTURELLI, D. (a cura di.). SASI-S. Strumento di Autovalutazione della Scuola (Infanzia - Secondaria). Milano: FrancoAngeli, 2008.

FERRARI, V. Elaborare e Costruire il DOCES (Dispositivo di Osservazione e Codifica dell'Esperienza Educativa). Tesi (Dottorato in Sanità pubblica e Scienze formative) Università degli studi di Pavia, 2006-2007.

GALDABINO, E. La giornata educativa all'asilo nido. In: BONDIOLI, A. (a cura di.). Il tempo nella quotidianità infantile. Azzano San Paolo (BG): Edizioni Junior, 2002. p. 19-29. [GALDABINO, E. O dia-a-dia educativo na creche. In: BONDIOLI, A. (Org.). O tempo no cotidiano infantil: perspectivas de pesquisa e estudos de caso. Tradução de: ORTALE, F. L.; MOREIRA, I. P. São Paulo: Cortez, 2004. p. 31-42].

HARMS, T.; CLIFFORD, R. M. SOVASI. Scala per l'Osservazione e la Valutazione della Scuola dell'Infanzia. (1980). Adaptação italiana de: FERRARI, M.; GARIBOLDI, A. Bergamo: Edizioni Junior, 1994.

HARMS, T.; CRYER, D.; CLIFFORD, R. M. Scala per la Valutazione dell'Asilo Nido. (1990). Adaptação italiana de: FERRARI, M.; LIVRAGHI, P. Milano: FrancoAngeli, 1992.

INSEGNAMENTI PEDAGOGICI DEL DIPARTIMENTO DI FILOSOFIA DELL'UNIVERSITÀ DI PAVIA (a cura di.). La giornata educativa nella scuola dell'infanzia. Bergamo: Edizioni Junior, 1993.

LE GOFF, J. (a cura di.). La nuova storia. (1979). Trad. it. Milano: Arnoldo Mondadori, 1980.

LE GOFF, J.; NORA, P. (a cura di.). Faire de l'histoire. Paris: Gallimard, 1974.

MARIN, L. Le portrait du roi. Paris: Les Éditions de Minuit, 1981.

MILANI, L. Scuola di Barbiana. Lettera a una professoressa. Firenze: Libreria editrice Fiorentina, 1967.

NIGITO, G. Tempi istituzionali, tempi di crescita: la gestione della quotidianità dei piccoli, dei medi e dei grandi nell'asilo nido. In: BONDIOLI, A. (a cura di.). Il tempo nella quotidianità infantile. Azzano San Paolo (BG): Edizioni Junior, 2002. p. 31-84. [NIGITO, G. Tempos institucionais, tempos de crescimento: a gestão do cotidiano dos pequenos, dos médios e dos grandes na creche. In: BONDIOLI, A. (Org.). O tempo no cotidiano infantil: perspectivas de pesquisa e estudos de caso. Tradução de: Ortale, F. L.; MOREIRA, I. P. São Paulo: Cortez, 2004. p. 43-95].

PITTURELLI, D. Una scala di autovalutazione della qualità della scuola: SASI-S (Strumento di Autovalutazione Scuola Infanzia-Secondaria). Tesi (Dottorato in Sanità pubblica, Scienze sanitarie e formative) - Università degli Studi di Pavia, 2005-2006. 
SABBATINI, A. La valutazione della professionalità docente. Gestione e valorizzazione del personale della scuola. Tesi (Dottorato in Sanità pubblica e Scienze formative) Università degli Studi di Pavia, 2009-2010.

SAVIO, D. La disponibilità a mettersi in gioco. In: BECCHI, E. (a cura di.). Manuale della scuola del bambino dai tre ai sei anni. Milano: FrancoAngeli, 1995a. p. 131-156.

SAVIO, D. "Teorie della mente", sviluppo della comunicazione verbale e capacità di selezionare le giuste premesse per le inferenze. Età Evolutiva, v. 52, 1995b. p. 34-54.

SAVIO, D. La valutazione del bambino nella scuola dell'infanzia secondo una lettura sistemica, socio-costruzionista e narrativista. In: BONDIOLI, A.; FERRARI, M. (a cura di.). Manuale di valutazione del contesto educativo: teorie, modelli, studi per la rilevazione della qualità della scuola. Milano: FrancoAngeli, 2000a. p. 289-306.

SAVIO, D. John Dewey e il 'lavorare per progetti': una connessione possibile. In: SAVIO, D. (a cura di.). La relazione educativa come processo d'indagine. Intenzionale, aperto, sistematico, controllato. Bergamo: Edizioni Junior, 2000b. p. 9-20.

SAVIO, D. Rilevare le caratteristiche organizzative e gestionali dei nidi e delle scuole dell'infanzia: storia e fisionomia di una batteria di questionari. In: BONDIOLI, A.; FERRARI, M. (a cura di.). Verso un modello di valutazione formativa. Ragioni, strumenti e percorsi. Azzano San Paolo (BG): Edizioni Junior, 2004. p. 535-602.

SAVIO, D. (a cura di). Il portfolio alla scuola dell'infanzia. Un pretesto per ricercare e negoziare identità. Azzano San Paolo (BG): Edizioni Junior, 2006.

SAVIO, D. L'osservazione del gioco simbolico al suo esordio: rilevare indizi e negoziare significati. In: BONDIOLI, A. (a cura di.). L'osservazione in campo educativo. Azzano San Paolo (BG): Edizioni Junior, 2007. p. 77-89.

SAVIO, D. Promuovere autovalutazione formativa: il percorso degli asili Nido della valle d'Aosta per la definizione delle linee guida. In: ZERBATO, R. (a cura di.). Infanzia: tempi di vita, tempi di relazione, XVI Convegno Nazionale Servizi Educativi per l'infanzia. Azzano San Paolo (BG): Edizioni Junior, 2008. p. 202-211.

SAVIO, D. Il gioco e la partecipazione del bambino: una sfida educativa e i suoi nodi. In: BONDIOLI, A.; SAVIO, D. (a cura di.). Partecipazione e qualità. Percorsi di condivisione riflessiva nei servizi per l'infanzia di Modena. Bergamo: Edizioni Junior, 2010. p. 205-254. [SAVIO, D. A brincadeira e a participação da criança: um desafio educativo e seus pontos nodais. In: BONDIOLI, A.; SAVIO, D. (Org.). Participação e qualidade em educação da infância: percursos e compartilhamento reflexivo em contextos educativos. Tradução de: FRITOLI, L. E. Curitiba: Editora UFPR, 2013. p. 243-303].

SAVIO, D. Il gioco e l'identità educativa del nido d'infanzia. Un percorso di valutazione formativa partecipata nei nidi di Modena. Bergamo: Edizioni Junior, 2011.

SCHÖN, D. A. Il professionista riflessivo. Per una nuova epistemologia della pratica professionale. (1983). Trad. it. Bari: Dedalo, 1993. 
SCHÖN, D. A. Formare il professionista riflessivo. Per una nuova prospettiva della formazione e dell'apprendimento nelle professioni. (1987). Trad. it. Milano: FrancoAngeli, 2006.

WOOD, D.; BRUNER, J. S.; ROSS, G. The role of tutoring in problem solving. Journal of Child Psychology and Psychiatry, v. 17, p. 89-100, 1976.

Texto recebido em 20 de abril de 2016. Texto aprovado em 20 de abril de 2016. 
